\title{
Effects of Oral Domoic Acid Exposure on Maternal Reproduction and Infant Birth Characteristics in a Preclinical Nonhuman Primate Model
}

\author{
Thomas M. Burbacher ${ }^{1,2,3}$, Kimberly S. Grant ${ }^{1,3}$, Rebekah Petroff ${ }^{1}$, Sara Shum ${ }^{4}$, Brenda \\ Crouthamel $^{1,3}$, Courtney Stanley ${ }^{1}$, Noelle McKain ${ }^{1,3}$, Jing Jing ${ }^{4}$, and Nina Isoherranen ${ }^{4}$ \\ ${ }^{1}$ Department of Environmental and Occupational Health Sciences, University of Washington, \\ Seattle, Washington, USA \\ ${ }^{2}$ Center on Human Development and Disability, University of Washington, Seattle, Washington, \\ USA \\ ${ }^{3}$ Washington National Primate Research Center, Seattle, Washington, USA \\ ${ }^{4}$ Department of Pharmaceutics, University of Washington, Seattle, Washington, USA
}

\begin{abstract}
Domoic Acid (DA) is a naturally-occurring excitotoxin, produced by marine algae, which can bioaccumulate in shellfish and finfish. The consumption of seafood contaminated with DA is associated with gastrointestinal illness that, in the case of high DA exposure, can evolve into a spectrum of responses ranging from agitation to hallucinations, memory loss, seizures and coma. Because algal blooms that produce DA are becoming more widespread and very little is known about the dangers of chronic, low-dose exposure, we initiated a preclinical study focused on the reproductive and developmental effects of DA in a nonhuman primate model. To this end, 32 adult female Macaca fascicularis monkeys were orally exposed to $0,0.075$ or $0.15 \mathrm{mg} / \mathrm{kg} / \mathrm{day}$ DA on a daily basis, prior to and during pregnancy. Females were bred to non-exposed males and infants were evaluated at birth. Results from this study provided no evidence of changes in DA plasma concentrations with chronic exposure. DA exposure was not associated with reproductive toxicity or adverse changes in the physical characteristics of newborns. However, in an unanticipated finding, our clinical observations revealed the presence of subtle neurological effects in the form of intentional tremors in the exposed adult females. While females in both dose groups displayed increased tremoring, the effect was dose-dependent and observed at a higher rate in females exposed to $0.15 \mathrm{mg} / \mathrm{kg} / \mathrm{day}$. These results demonstrate that chronic, low-level exposure to DA is associated with injury to the adult CNS and suggest that current regulatory guidelines designed to protect human health may not be adequate for high-frequency shellfish consumers.
\end{abstract}

Corresponding author: Thomas M. Burbacher, School of Public Health, Department of Environmental and Occupational Health Sciences, 1959 NE Pacific St, Box 357330, University of Washington, Seattle, WA, 98195, tmb@uw.edu.

Publisher's Disclaimer: This is a PDF file of an unedited manuscript that has been accepted for publication. As a service to our customers we are providing this early version of the manuscript. The manuscript will undergo copyediting, typesetting, and review of the resulting proof before it is published in its final citable form. Please note that during the production process errors may be discovered which could affect the content, and all legal disclaimers that apply to the journal pertain.

Conflict of interest statement

The authors report no conflicts of interest. The authors alone are responsible for the content and writing of the paper. 


\section{Keywords}

domoic acid; oral exposure; prenatal; neurotoxicity; reproduction; infant; nonhuman primate

\section{Introduction}

The six oceans of the world, the Arctic, Atlantic, Indian, Pacific and Southern, cover over $70 \%$ of the planet's surface and comprise the largest ecosystem on earth. Within the ocean environment, there are thousands of microalgae species that play a positive role in producing thriving fisheries and rich feeding grounds for marine animals and seabirds. There are also a small number of microalgae that produce dangerous biotoxins and these species are referred to as Harmful Algal Blooms (HABs) (Centers for Disease Control and Prevention, 2017; Wells et al., 2015). HABs have been linked to large-scale killings of wildlife and are responsible for over 60,000 cases of human poisoning each year (Berdalet et al., 2016; Grattan et al., 2016b; Stommel and Watters, 2004). Domoic Acid (DA), the focus of this paper, is a naturally-occurring neurotoxin that is produced by harmful algae in the genus Pseudo-nitzschia (Bates et al., 1989; Garrison et al., 1992). A member of the kainoid class of excitatory neurotransmitters, DA is transferred up the food chain through bioaccumulation and elevated levels have been documented in mussels, oysters, razor clams, scallops, sardines, anchovies, crab and lobster. Shellfish and small finfish accumulate this toxin because they feed on the toxic algae that produce DA, and the primary route of exposure for humans is the consumption of contaminated shellfish meat and viscera (Lefebvre and Robertson, 2010). The algal blooms that produce this marine biotoxin are becoming more frequent, and in the summer of 2015, a Pseudo-nitzschia bloom off the Western coast of the United States was so massive it extended from the central California coast to the Alaska Peninsula and triggered an unprecedented number of beach closures to shellfish harvesting (McCabe et al., 2016). Warm ocean conditions and nutrient enrichment from seasonal upwelling have been identified as factors that are driving the increased occurrence and severity of these damaging blooms (Mckibben et al., 2017; Zhu et al., 2017).

Exposure to DA can cause illness and death in humans and animals and is a growing public health concern in many coastal dwelling communities (Lefebvre and Robertson, 2010; Ramsdell and Gulland, 2014). The largest human episode of DA poisoning occurred on Prince Edward Island in Canada with 153 cases of acute intoxication and 4 deaths after victims consumed a meal of contaminated mussels (Perl et al., 1990b, 1990a). The outbreak in Canada provided vital data on acute, high-level exposure, and estimated patient exposures ranged from 60 to $290 \mathrm{mg} \mathrm{DA} /$ patient or about 1 to $5 \mathrm{mg} / \mathrm{kg}$ for a $60 \mathrm{~kg}$ person (Jeffery et al., 2004; Perl et al., 1990a). Subjects with overt symptoms of DA poisoning exhibited effects characterized by initial gastrointestinal illness (e.g. nausea, vomiting, diarrhea) that in some cases, evolved into a spectrum of responses ranging from agitation/confusion to hallucinations, memory loss, seizures and coma (Teitelbaum et al., 1990b, 1990a). The term Amnesic Shellfish Poisoning originated from clinical observations that memory functions were significantly impaired in some DA-sickened patients, even after recovery from overt signs of illness. Patient autopsies revealed neuronal loss and necrosis that were concentrated primarily in the amygdala and hippocampal regions of the brain. While there have been no 
significant, verified episodes of human DA poisoning since 1987, rising DA levels in ocean waters have been associated with the large-scale killing of marine mammals and seabirds (Lefebvre et al., 2016, 2002). It has been suggested that ocean-dwelling wildlife are acting as sentinel species for the human health risks associated with exposure to this dangerous and increasingly widespread neurotoxin (Backer and Miller, 2016; Bossart, 2011). Over 123 million Americans live in a county directly on the shoreline (National Ocean Service, National Oceanic and Atmospheric Administration (NOAA)). Thus, the physical well-being of marine mammals who inhabit the same coastal environments as humans is vitally important to understanding the biological threat that DA poses to human health.

In an effort to protect human health from the adverse effects of acute high-level DA exposure, regulatory and environmental protection agencies have established a threshold of $20 \mathrm{ppm}$ in razor clam meat as the level at which coastal beaches are closed to commercial and recreational shellfish harvesting (Mariën, 1996; Wekell et al., 2004). This level is based on estimates of DA exposure and effects from the Prince Edward Island poisoning.

Researchers and environmental health agencies have also proposed various estimates of DA intake that protect public health. Proposed estimates for repeated exposure to DA or the Tolerable Daily Intake (TDI) vary from 0.075 to $0.1 \mathrm{mg} / \mathrm{kg} / \mathrm{day}$. These values are based on data from the Prince Edward Island poisoning or results from laboratory studies using nonhuman primates (FAO, 2004; Toyofuku, 2006; Marien, 1996). On the Western coast of the United States, more frequent algal blooms are resulting in the persistent contamination of shellfish with detectable levels of DA that do not reach the $20 \mathrm{ppm}$ threshold. Individuals who regularly harvest and consume shellfish with elevated, but permissible levels of DA (under $20 \mathrm{ppm}$ ), are being chronically exposed to this marine biotoxin (Ferriss et al., 2017). Coastal-dwelling tribal nations are at particularly high-risk for long-term, low-dose exposure because of their reliance on the ocean as an essential economic resource, foundation of cultural identity and year-round food source. A dietary survey of tribal members living on three Native American reservations in Washington State found that $84 \%$ of respondents indicated recent razor clam consumption (Boushey et al., 2016; Fialkowski et al., 2010). The impact of chronic DA exposure was recently studied in these communities and exposure (as measured by the consumption of razor clams) was associated with decrements in memory that were serious enough to affect everyday living skills (Grattan et al., 2016a, 2018). This striking research finding suggests that chronic exposure to low-level DA from harvested shellfish is not without risk to the adult central nervous system. The growing significance of DA as an environmental threat demands that contemporary exposure scenarios be considered in the development of regulatory thresholds to protect human health. Very little is known about the impact of chronic, lower-level oral exposure and this is particularly the case for sensitive subgroups such as the developing fetus, infants and elders.

While preclinical work has been extremely valuable in defining the health risks of DA exposure, most studies have focused on the effects of acute, high-dose exposures in adult subjects using non-oral routes of exposure such as intraperitoneal (IP) and intravenous (IV) treatment (Grant et al., 2010). Reported signs of DA toxicity in mature monkeys and rodents are similar to those observed in the human poisoning cases and effects include hippocampal damage, adverse neurological effects (e.g. seizures) and the disruption of cognitive processes (Lefebvre et al., 2017; Scallet et al., 2004, 1993, Tryphonas et al., 1990a, 1990b). The 
reproductive and developmental effects of DA exposure have not been studied in humans or nonhuman primates, but the preclinical rodent literature suggests a marked fetal vulnerability (Dakshinamurti et al., 1993; Xi et al., 1997). Consequences of early life exposure include hippocampal damage (sometimes progressive in nature), seizure disorders and persistent changes in a number of behavioral domains, particularly memory, social behavior and emotional reactivity (see Doucette and Tasker, 2016 for review). Adverse effects in young animals are observed at levels of exposure up to 40 times lower than those required to produce neurotoxicity in adults.

The protection of human health, particularly in vulnerable groups such as developing fetuses, will depend upon our understanding of this chemically-complex compound when ingested orally at low doses on a chronic basis. To address this growing public health concern, we initiated a longitudinal, birth-cohort study to investigate the maternal reproductive and offspring developmental effects of chronic, low-level, oral DA exposure in nonhuman primates. Preclinical model systems offer the ability to control many of the confounding environmental variables that can adversely impact sensitive outcome measures in human epidemiological studies and can provide an important connection between brain and behavior (Thompson et al., 2009). In this investigation, we selected the macaque monkey to model human exposure effects over pregnancy because of shared reproductive attributes between the two species (e.g. similarities in the morphology and physiology of the ovaries, the presence of discoid, hemochorial placentas and prolonged pregnancies (Buse et al., 2003; Carter, 2007; King, 1993). To increase the translational impact of study results, DA doses were carefully selected to mimic chronic exposure at or near the proposed Tolerable Daily Intake (TDI) for humans (Costa et al., 2010; Mariën, 1996; Toyofuku, 2006). This manuscript presents the first data from primates that addresses the maternal and fetal risks of this biological marine contaminant and provides insight into the adequacy of current environmental regulations to protect the human health in high-frequency shellfish consumers.

\subsection{Materials and Methods}

\subsection{Chemicals and Reagents}

DA was purchased from BioVectra (Charlottetown, PE, Canada). Certified calibration solution for DA was purchased from National Research Council Canada (Ottawa, ON, Canada). Optima grade water, methanol, acetonitrile, and formic acid used for bioanalytical assays were purchased from Fisher Scientific (Pittsburgh, PA).

\subsection{Subjects}

Thirty-two adult female and 3 adult male Macaca fascicularis were acquired for the study. The females were pseudo-randomly assigned to either a control group $(\mathrm{N}=10)$, a 0.075 $\mathrm{mg} / \mathrm{kg} /$ day DA group $(\mathrm{N}=11)$ or a $0.15 \mathrm{mg} / \mathrm{kg} /$ day DA group $(\mathrm{N}=11)$ to establish groups with similar ages and weights. Females ranged in age from 5.5 to 11 years with an average age of approximately 7 years across the groups. Females ranged in weight from 2.8 to $4.2 \mathrm{~kg}$ with an average weight at assignment of approximately $3.5 \mathrm{~kg}$ across the groups. All females 
were nulliparous. Males were 7.5, 7.7, and 8.4 years of age and weighed 7.9, 5.9 and $5.4 \mathrm{~kg}$ at the beginning of the study. Males had no breeding experience.

\subsection{Study Design}

All animal procedures strictly followed the Animal Welfare Act and the Guide for Care and Use of Laboratory Animals of the National Research Council. All protocols were approved by the University of Washington Institutional Animal Care and Use Committee to meet the highest standards of ethical conduct and compassionate use of animals in research. During the study, adult females were housed in individual communicating cages that were equipped with grooming bars that allowed adjacent females contact 24 hours/day. Frozen treats, fresh fruit and vegetables, music, movies and toys were provided on a routine basis. The adult males were housed individually in a separate room away from the females and provided the same food and enrichments. Animal housing rooms was kept at $\sim 75$ degrees and lights were on a 12 hour on and 12 hour off schedule.

The study design was based on previous reproductive and developmental toxicology studies conducted in our laboratory (Burbacher et al., 2004, 1988). The study included a training period where protocols were implemented to train females to drink from a syringe, collect blood for DA analysis without sedation, evaluate general health status (weights, medications), observe signs of DA toxicity (Clinical Observations), and detect menstrual bleeding. Once females were trained, experimental protocols were conducted for 2 months without DA exposure (pre-DA exposure period). During this period females were orally dosed on a daily basis with the dosing vehicle solution alone (5\% sucrose in water). Daily, oral exposure to DA was then initiated for the 2 DA exposure groups (the controls continued to receive the dosing vehicle alone) and dosing continued for another 2 months prior to breeding and then throughout breeding (pre-pregnancy DA exposure period) and pregnancy (pregnancy DA exposure period). Experimental protocols continued throughout these periods. Males were not exposed to DA.

\subsection{Daily DA Dosing Protocol}

Dosing solutions in 5\% sucrose were prepared fresh every week. Briefly, sucrose was weighed to prepare a $5 \%(\mathrm{w} / \mathrm{v})$ sucrose solution in tap water. DA powder was weighed and dissolved in the $5 \%$ sucrose solution to produce a $1 \mathrm{mg} / \mathrm{mL}$ DA solution. The DA solution was sonicated for 15 minutes to ensure complete dissolution and filtered subsequently using a syringe filter $(0.2$ microm, $25 \mathrm{~mm})$. The filtered $1 \mathrm{mg} / \mathrm{mL}$ DA solutions were subsequently diluted according to the animals' weights with filtered sucrose solution. The prepared individual dosing solutions were stored in $16 \mathrm{~mL}$ glass vials at $4^{\circ} \mathrm{C}$ until use. Prior to pregnancy, females were dosed according to their last weekly weight. During pregnancy, females were dosed according to their last pre-pregnant weight. Syringes were labeled with only the animal number and week to ensure all testers remained blind to the exposure groups. Dosing occurred at approximately the same time every morning ( 9 AM), seven days a week. Dosing solutions were analyzed for DA content by LC-MS/MS to confirm DA concentrations (Shum et al., 2018). Females were fed Lab Diet High Protein Monkey Diet biscuits approximately 2 hours before the daily DA dosing and again approximately 5 hours after dosing. 


\subsection{Blood Collection and DA Analysis Protocols}

Blood samples were collected every two weeks for DA quantification across the study. Blood collections occurred approximately 5 hours after dosing with sucrose during the baseline period and alternated between collections at 5 hours post DA dosing or 24 hours post DA dosing during the exposure periods. Blood samples were also collected at delivery. Sedation was not used for the bi-weekly blood collection because the animals were trained to provide their leg for the blood draw. Blood was drawn from the great saphenous vein into sodium heparin tubes and centrifuged at 3,000 $\mathrm{x} g$ for 15 minutes to isolate plasma for analysis. Plasma was stored at $-20^{\circ} \mathrm{C}$ until analysis. DA was measured using a recently developed and validated LC-MS/MS method (Shum et al., 2018). The lower limit of detection (LOD) was $0.16 \mathrm{ng} / \mathrm{mL}$ and the lower limit of quantitation (LLOQ) was 0.31 $\mathrm{ng} / \mathrm{mL}$ of DA in monkey plasma.

\subsection{Maternal Health Assessments}

Maternal Weight: All females were weighed once per week during the investigation. Animals were trained to voluntarily enter a transfer box which was placed on a digital scale where values (minus the weight of the transfer box) were recorded in kilograms.

Maternal Medications: Females were observed for signs of diarrhea, lethargy, weight loss, on a daily basis by study personnel. Females exhibiting signs of illness were reported to the attending veterinarian and medications were prescribed if necessary. Information regarding the type, dosage, and duration of various medications were recorded.

Clinical Observations: A Clinical Observation Test developed previously (see Burbacher et al., 1999, 2004) was used to provide a rapid evaluation of the visual functioning and motor coordination of the females. Females were typically observed at least 3 times per week, $\sim 5$ hours after dosing. Testers initially presented a small piece of fruit approximately 6 to 10 inches from the cage and recorded whether or not the females visually oriented to the fruit. The fruit was then moved to the left or right and recorded whether or not the females visually followed the fruit. Testers recorded the absence or presence of visual orientation as well as whether a full, partial or no follow was observed during the trial. Testers then placed the small piece of fruit or cereal in the palm of their hand and held it approximately 6 to 8 inches from the cage so the females had to reach out and pick up the treat. The tester observed whether or not hand and/or arm tremors were observed during the reach. Fine motor coordination was also evaluated by noting whether or not the female was able to retrieve the fruit reward. Three "reaching" trials were presented during each session. In addition to the above, testers recorded vomiting, scratching, resting tremors or seizure-like activity, lethargy or any other abnormal behavior during the observation test. A lead technician conducted the assessment throughout the study and was the primary tester and "keeper of the code". Two additional technicians were involved, one collecting data during the early stages of the study, the other during the latter part. Technicians were equally represented across the different DA exposure groups. The primary tester conducted reliability sessions with the other testers every 6 to 8 months throughout the study (reliability criteria $=80 \%$ for each outcome). All testers were blind to the exposure history of the females. Study technicians and nursery staff also recorded observations of vomiting, 
diarrhea or any abnormal behaviors throughout the day and reported these observations to the clinical staff.

\subsection{Maternal Reproductive Assessments}

Tracking Menstrual Bleeding: Using positive reinforcement and behavioral shaping, animals were trained to voluntarily present their perineum for visual inspection to detect menstrual bleeding. A flashlight was used to help examiners and serve as a cue and animals were rewarded with a treat after turning, lifting their tail and allowing a brief visual inspection. The first day that bleeding was detected was consider Day 1 of the menstrual cycle. Observations for menstrual bleeding occurred seven days a week.

Breeding: Females were bred with one of three nonexposed males after 4 menstrual cycles were observed ( 2 prior to DA exposure and 2 after DA exposure had begun). For the initial breeding, females were placed with one of the males for approximately 4 hours per day for 7 days during mid-cycle (days 7-13). The same male was used across the 7 days of breeding. If the female did not conceive, the same procedure was used with a different male for the second breeding. For the $3^{\text {rd }}$ breeding, females were placed with a different male (from the initial 2) for approximately 4 hours per day for 9 days during mid-cycle (days 7-15). Again, the same male was used across the 9 days of breeding. If females did not conceive after 3 breedings, they were placed with one of the males for approximately 4 hours a day during their entire menstrual cycle for their 4 th and subsequent breedings. A maximum of 7 breedings occurred and males were assigned to females to counterbalance the number of infants from each sire in the individual DA exposure groups. Females were visually checked for the presence of semen (providing evidence that mating occurred) after each breeding. Day 10 of the menstrual cycle was considered the day of conception (gestation day 0) for the all of the breedings. Pregnancy was confirmed with a progesterone blood assay by 25 days of gestation.

Monitoring Pregnancy and Delivery: As mentioned above, females were observed on a daily basis by study personnel. Beginning at approximately 135 days of pregnancy, females were observed for the onset of labor during the evening ( $6 \mathrm{pm}$ to $6 \mathrm{am}$ ) every 30 minutes via infrared camera by nursery staff. When signs of active labor were observed, a delivery team was summoned to the laboratory in order to separate the newborn at birth to begin our postnatal assessments. Adult females were sedated with ketamine (IM, $5 \mathrm{mg} / \mathrm{kg}$ ) after they delivered and the infant was placed in a preheated incubator for transport to a specialized nursery for evaluation. Adult females were monitored by nursery staff on camera until fully recovered from sedation. If delivery complications occurred (e.g. prolonged labor, abnormal delivery position), the veterinary staff was immediately notified that assistance was needed. Veterinarians with extensive primate experience made all clinical decisions related to labor and delivery and were fully empowered to determine when the labor process was not progressing normally and a cesarean section was required to protect the well-being of the mother and infant. 


\subsection{Newborn Procedures}

All examiners were blind to the prenatal exposure history of the infants and had been extensively trained on all data collection measures.

Newborn Weights and Anthropometrics: Newborns were weighed and an anthropometric exam was administered to measure crown-rump length and head circumference, width and length according to procedures previously described (Burbacher et al., 2004). Briefly, crown-rump length was measured by placing the infant in a supine position on a metal sliding scale with its rump against the base of the scale and its crown against a sliding barrier. The distance between the top of the infant's head and the rump was measured. Head circumference was measured with use of a measuring tape that was placed around the infant's head below the brow ridge, along the nuchal crest and above the ears, thus covering the occiput. Head width and length were measured using spreading calipers. Head width was measured using landmarks just above and in front of the ears, which provided a measure of the two widest points of the skull. Head length was measured using the length from the area between the eyes to the occiput. Two measurements (in millimeters) were made by reliable testers and the mean measurement was used for analysis.

Newborn Health Status (Apgar) and Screening for Congenital Defects: A procedure to measure newborn health status modeled after the human Apgar exam (Apgar, 1953) was administered twice, once within 30 minutes after birth and then again $\sim 1$ hour after birth. The exam includes measures of heart rate, respiration, temperature, muscle tonicity, physical activity and skin color. A screening exam for physical birth anomalies was also undertaken within the first 24 hours that focused on the skin (pigmentation, rash, bruises, edema), head (molding, fontanel, depressions, overriding suture), face (symmetry, mouth, eyes, ears, teeth), trunk (sternal retraction, spine, breasts, neck), genitals (vagina, anus, penis, scrotum) and extremities (digits, limbs).

Blood Collection: Blood samples were collected from the femoral vein of non-sedated offspring on postnatal day 1 . Blood was processed according to the procedures described above.

\subsection{Statistics and Results}

\subsection{Maternal DA Exposure}

The duration of DA exposure for the adult females ranged from 79 to 233 days at conception and 232 to 403 days at delivery and was largely dependent on the number of breedings required for a conception (see Table 1). While the overall range is quite large, the results of one-way analysis of variance (ANOVA) tests did not indicate a significant difference in the number of days exposed to DA (or sugar solution) at conception and delivery as a function of DA exposure group (conception, $\mathrm{F}(2,26)=0.67$, $\mathrm{p}=0.52$; delivery, $\mathrm{F}(2,26)=0.55$, $\mathrm{p}=0.58$ ).

Maternal Plasma DA Concentrations: The results of the bi-weekly blood draws are shown in Figure 1 and Table 2. Samples that were above the LOD $(0.16 \mathrm{ng} / \mathrm{mL})$ but below 
the LLOQ $(0.31 \mathrm{ng} / \mathrm{mL})$ for DA were designated as Below Limit of Quantitation (BLQ) and assigned the value $0.24 \mathrm{mg} / \mathrm{ml}$ (half way in between the LOD and the LLOQ). DA was not detected in any plasma samples during the Pre-Exposure period. Once DA exposure began, plasma DA concentrations varied with continuous DA exposure prior to pregnancy. Plasma DA concentrations at 5 hours post-dosing ranged from $0.24 \mathrm{ng} / \mathrm{ml}$ to $5.26 \mathrm{ng} / \mathrm{ml}$ for the $0.075 \mathrm{mg} / \mathrm{kg} /$ day exposure group and $0.37 \mathrm{ng} / \mathrm{ml}$ to $10.01 \mathrm{ng} / \mathrm{ml}$ for the $0.15 \mathrm{mg} / \mathrm{kg} /$ day exposure group. Plasma DA concentrations at 24 hours post-dosing ranged from $0.24 \mathrm{ng} / \mathrm{ml}$ to $2.36 \mathrm{ng} / \mathrm{ml}$ for the $0.075 \mathrm{mg} / \mathrm{kg} /$ day exposure group and $0.24 \mathrm{ng} / \mathrm{ml}$ to $5.61 \mathrm{ng} / \mathrm{ml}$ for the $0.15 \mathrm{mg} / \mathrm{kg} /$ day exposure group. The results of one-way ANOVA tests using the mean individual blood DA concentrations for each female prior to pregnancy (or at the end of breeding for females who did not conceive) indicated that plasma DA concentrations were significantly higher for the $0.15 \mathrm{mg} / \mathrm{kg} /$ day exposure group compared to the 0.075 $\mathrm{mg} / \mathrm{kg} /$ day exposure group at both sample time-points ( 5 hour sample, $\mathrm{F}(1,20)=28.48$, $\mathrm{p}<0.01 ; 24$ hour sample, $\mathrm{F}(1,20)=27.66, \mathrm{p}<0.01)$.

Plasma DA concentrations continued to vary during pregnancy. Plasma DA concentrations at 5 hours post-dosing ranged from $0.24 \mathrm{ng} / \mathrm{ml}$ to $5.26 \mathrm{ng} / \mathrm{ml}$ for the $0.075 \mathrm{mg} / \mathrm{kg} /$ day exposure group and $0.37 \mathrm{ng} / \mathrm{ml}$ to $9.16 \mathrm{ng} / \mathrm{ml}$ for the $0.15 \mathrm{mg} / \mathrm{kg} /$ day exposure group. Plasma DA concentrations at 24 hours post-dosing ranged from $0.24 \mathrm{ng} / \mathrm{ml}$ to $2.36 \mathrm{ng} / \mathrm{ml}$ for the 0.075 $\mathrm{mg} / \mathrm{kg} /$ day exposure group and $0.24 \mathrm{ng} / \mathrm{ml}$ to $4.63 \mathrm{ng} / \mathrm{ml}$ for the $0.15 \mathrm{mg} / \mathrm{kg} /$ day exposure group during pregnancy. The results of one-way ANOVA tests using the mean individual blood DA concentrations for each female during pregnancy again indicated that plasma DA concentrations were significantly higher for the $0.15 \mathrm{mg} / \mathrm{kg} /$ day exposure group compared to the $0.075 \mathrm{mg} / \mathrm{kg} /$ day exposure group at both sample time-points ( 5 hour sample, $\mathrm{F}(1,18)=$ $18.27, \mathrm{p}<0.01 ; 24$ hour sample, $\mathrm{F}(1,18)=24.14, \mathrm{p}<0.01)$. Finally, a repeated measures ANOVA comparing the mean DA plasma concentrations prior to pregnancy with those during pregnancy indicated a significant difference for the 5- hour sample $F(1,18)=5.53$, $\mathrm{p}=0.03$ ). Five-hour DA blood concentrations were significantly lower during pregnancy for both DA exposure groups. No significant differences were observed for the 24-hour sample.

\subsection{Maternal Health Assessments}

Maternal Weight: Maternal weights were similar across the DA exposure groups throughout the study (see Table 3). Except for 1 female, weights changed little once DA exposure began. One female in the $0.075 \mathrm{mg} / \mathrm{Kg} / \mathrm{day}$ DA exposure group was removed from the study during the breeding period after she exhibited weight loss and amenorrhea. The results of a two-way ANOVA comparing the weights of the 3 DA exposure groups across the baseline and pre-pregnancy DA exposure periods did not indicate a significant difference due to DA exposure group $(\mathrm{F}(2,28)=0.46, \mathrm{p}=0.67)$, or an interaction of DA exposure group and DA exposure period $(\mathrm{F}(2,28)=0.79, \mathrm{p}=0.46)$. A main effect of DA exposure period was observed, indicating an increase in the weight of females during the pre-pregnancy period $(\mathrm{F}(1,28)=18.83, \mathrm{p}<0.01)$. For those females who conceived, the results of a one-way ANOVA did not indicate a significant difference in the average weight during pregnancy due to DA exposure group $(\mathrm{F}(2,26)=0.78, \mathrm{p}=0.47)$. Weight gain during pregnancy was also similar across the $3 \mathrm{DA}$ exposure groups $(\mathrm{F}(2,26)=0.63, \mathrm{p}=0.54)$. 
Maternal Medications: All females were sedated with approximately $10 \mathrm{mg} / \mathrm{kg} \mathrm{IM}$ ketamine for mandatory tuberculosis testing approximately 1 month before breeding. During the early stages of the study (prior to pregnancy), six females required treatment for minor injuries incurred during socialization. These treatments generally included at least one pain medication (ketoprofen, meloxicam, buprenorphine or lidocaine) and at least one antibiotic (cephalexin, cefazolin, or penicillin). In addition, two females required treatment during pregnancy. One was treated with acetaminophen and a single dose of penicillin and buprenorphine. The other female was treated with acetaminophen, buprenorphine and bupivacaine. For C-section deliveries, females were pre-anesthetized with ketamine (5-10 $\mathrm{mg} / \mathrm{kg}$ i.m. $)$ and atropine $(0.04 \mathrm{mg} / \mathrm{kg}$ i.m. $)$ and maintained on inhaled sevoflurane $(0.8-$ $2.5 \%$ ) and $100 \%$ oxygen. Thus, the overall incidence of females requiring therapeutic agents was quite low.

Clinical Observations: The results of the Clinical Observations Test did not indicate the presence of acute signs of DA toxicity (vomiting, retching, resting tremors or seizures) or effects on visual functioning or gross motor coordination. The results did reveal, however, that long-term exposure to DA was related to an increase in observations of subtle arm/hand tremors during the reaching task. For each of the 3-trial sessions, tremors were noted as "present" if observed on 2 of the 3 trials (confirmation of a tremor observation was critical for tester reliability). Figure 2 displays the "tremor rates" (the \% of sessions that tremors were observed on 2 of the 3 trials) for the 2 month pre-DA exposure period and then over 1 month increments during DA exposure until delivery (or end of breeding for females who did not conceive). Tremors were not observed for the majority of the females ( 25 out of 32 females) during the Pre-DA exposure period. Five females exhibited tremors on less than $10 \%$ of the sessions while 2 females exhibited higher tremor rates $(16 \%$ and $26 \%$ of sessions). Females with tremors during the pre-DA exposure period were from all 3 exposure groups ( 2 from controls, 3 from the $0.075 \mathrm{mg} / \mathrm{kg} /$ day and 2 from the 0.15 $\mathrm{mg} / \mathrm{kg} /$ day DA exposure groups). Tremor rates varied a great deal during DA exposure. Rates varied over time for a number of females in each of the DA exposure groups. Tremor rates for some females began to increase during the $1^{\text {st }}$ or $2^{\text {nd }}$ month after DA exposure began. For other females, rates increased later, after several months of DA exposure. Given the different patterns of tremor responses over time, we calculated the tremor rate over the entire DA exposure period up until delivery (or end of breeding) for each female. "Tremor increase scores" ( $\%$ tremors observed during the entire DA exposure period minus the $\%$ tremors observed during the 2 month pre-DA exposure period) were then calculated for each female for the analysis. The average tremor increase scores for the 3 DA exposure groups were $9.6 \% \pm 4.2 \%$ for the controls, $17.7 \% \pm 4.1 \%$ for the $0.075 \mathrm{mg} / \mathrm{kg} /$ day DA exposure group, and $30.5 \% \pm 8.3 \%$ for the $0.15 \mathrm{mg} / \mathrm{kg} / \mathrm{day}$ DA exposure group (see Table 4). A oneway ANOVA comparing the tremor increase scores across the 3 DA exposure groups did not indicate a significant difference due to DA exposure $(F(2,28)=3.10, p=0.06)$. One control female exhibited high tremor rates throughout the study. MRI analysis of the brain of this female revealed lesions in the temporal lobe (see discussion for further details). Thus, a second one- way ANOVA was conducted excluding this female. The results of that analysis indicated a significant difference due to DA exposure $(\mathrm{F}(2,27)=4.51, \mathrm{p}=0.02)$. Post-hoc Bonferroni analysis indicated a significant difference between the controls and the 0.15 
$\mathrm{mg} / \mathrm{kg} /$ day DA exposure group. One of the hypotheses for why the patterns of tremor responses were so different across the exposure period was that females may have been more susceptible during pregnancy. To test this hypothesis, a secondary analysis was conducted to examine how much of the increase in $\%$ tremors took place prior to pregnancy compared to during pregnancy. Separate paired t-tests for each of the DA exposure groups comparing the increase in \% tremors from the pre-DA exposure period to conception to the increase in $\%$ tremors from conception to delivery did not indicate a significant difference for any of the DA exposure groups ( $p>0.20$, all tests). Thus, there was not evidence that tremeors increased at a higher rate during pregancy.

\subsection{Maternal Reproduction}

Tracking Menstrual Bleeding: All females demonstrated 4 menstrual cycles prior to breeding, 2 cycles during the pre DA expsoure period and 2 cycles once DA exposure began. There was little change in the length of the menstrual cycle over time. The results of a repeated measures analysis of variance examining changes in the menstrual cycle length for the initial 4 cycles did not indicate a significant main effect of DA exposure group on the length of the menstrual cycle $(\mathrm{F}(2,29)=1.46, \mathrm{p}=0.26)$, or an interaction of DA exposure group and cycle number $(1-4)(F(6,87)=0.84, \mathrm{p}=0.54)$. No main effect of cycle \# was observed as well $(\mathrm{F}(3,87)=0.09, \mathrm{p}=0.97)$. The average menstrual cycle lengths across the 3 DA exposure groups ranged from 29 to 33 days, normal for fascicularis macaques (see Table $5)$.

Breeding: Conception rates were high (90\%-100\%) for all DA exposure groups (see Table 6). While the number of breedings required for a conception varied widely (1 to 7), the average number of breedings to conception across the DA exposure groups varied only slightly, from 2.1 to 2.6. A one- way ANOVA comparing the number of breedings required for a conception across the 3 DA exposure groups did not indicate a significant difference due to DA exposure $(\mathrm{F}(2,26)=1.85, \mathrm{p}=0.18)$. Only 8 of the 31 females required more than 3 breedings (breeding throughout the menstrual cycle) and these females were spread across the 3 DA exposure groups.

Pregnancy and Delivery: Delivery complications occurred frequently in all DA exposure groups, resulting in high cesarean (C-) section delivery rates. Over half of the control and $0.075 \mathrm{mg} / \mathrm{kg} /$ day DA females and nearly two-thirds of $0.15 \mathrm{mg} / \mathrm{kg} /$ day DA females were delivered via $\mathrm{C}$-section. Decisions regarding $\mathrm{C}$-sections were made by the attending veterinarians from the Primate Center, who were blinded to the treatments. The policy of the Primate Center is to err on the side of caution to minimize fetal loss. Seven females were Csectioned for unproductive labor, defined as active labor for at least 2 successive nights. Four females were $\mathrm{C}$-sectioned for excessive vaginal bleeding (blood covering vaginal surface) and 7 females were $\mathrm{C}$-sectioned following an unsedated ultrasound examination after an evening of active labor revealed fetal distress (low fetal hear rate), breech presentation, or Placenta Previa (placenta covering most of the cervix) (see Table 6). All C-section deliveries occurred after 150 days gestation and none of the $\mathrm{C}$-sectioned infants displayed signs of premature birth (e.g. low-birthweight, irregular heart rate, inability to control body temperature). While the $\mathrm{C}$-section delivery rate was high, so was the livebirth delivery rate, 
with only 1 pregnancy ending in a nonviable offspring for the entire study (see Table 6). One female in the $0.15 \mathrm{mg} / \mathrm{kg} /$ day DA exposure group had a breech delivery. The newborn was delivered via C-section but was not breathing and could not be resuscitated. Nine live-born infants (5 males and 4 females) were delivered in the control group, 9 (5 males and 4 females) in the $0.075 \mathrm{mg} / \mathrm{kg} /$ day DA exposure group and 10 (4 males and 6 females) in the $0.15 \mathrm{mg} / \mathrm{kg} /$ day DA exposure group. The control group included 3 infants from each of the sires. The $0.075 \mathrm{mg} / \mathrm{kg} / \mathrm{day}$ DA exposure group included 5 infants from sire- 1 and 2 infants from sire- 2 and sire- 3 . The $0.15 \mathrm{mg} / \mathrm{kg} / \mathrm{day}$ DA exposure group include 4 infants from sire-1, 3 infants from sire- 2 and 4 infants from sire-3.

Given the high rate of C-sections in the study, a preliminary two-way analysis of variance comparing the length of pregnancy for the females who were C-sectioned to those who delivered vaginally for the DA exposure groups did not indicated a significant main effect of DA exposure group $(\mathrm{F}(2,23)=0.69, \mathrm{p}=0.51)$, delivery type $(\mathrm{F}(1,23)=0.67, \mathrm{p}=0.42)$ or an interaction of DA exposure group and delivery type $(\mathrm{F}(2,23)=1.12, \mathrm{p}=0.34)$. A follow-up one- way ANOVA comparing the length of pregnancies across the 3 DA exposure groups did not indicate a significant difference due to DA exposure $(\mathrm{F}(2,26)=0.16, \mathrm{p}=0.86)$. The average pregnancy length across the DA exposure groups varied slightly from 160 to 162 days (see table 7).

\subsection{Newborn Procedures}

Newborn Weights and Anthropometrics: Birthweights and newborn anthropometric measures are displayed in Table 8 . One $0.15 \mathrm{mg} / \mathrm{kg} /$ day female infant was vaginally delivered pre-term ( $<150$ days) and had the lowest birthweight at 240 grams. The remaining infants exhibited birthweights and anthropometric measures consistent with normal full-term newborns for this species (Burbacher et al., 1988; Naiken et al., 2015) Preliminary two-way ANOVAs were run to examine whether or not gestation length impacted birthweights or anthropometric measures. The results of these analyses did not indicate a significant main effect of gestation length or DA exposure on any of the newborn parameters ( $p>0.10$, all tests), or an interaction of gestation length and DA exposure ( $p>0.10$, all tests). Two-way ANOVAs were also run to examine whether or not delivery type (C-section or vaginal) impacted birthweights or anthropometric measures. The results of these ANOVAs did not indicate a significant main effect of delivery type or DA exposure on any of the newborn parameters ( $p>0.10$, all tests), or an interaction of delivery type and DA exposure ( $p>0.10$, all tests). Results of two-way ANOVAs examining the effects of sex of the infant on birthweights and anthropometric measures for the 3 DA exposure groups not indicate a significant main effect of DA exposure on any of the newborn parameters ( $p>0.10$, all tests), or an interaction of DA exposure and sex of the infant ( $p>0.10$, all tests). There were, however, significant main effects of sex of the infant on birthweight $(\mathrm{F}(1,22)=4.66$, $\mathrm{p}=0.04)$, head circumference $(\mathrm{F}(1,22)=5.90, \mathrm{p}=0.02)$, and head length $(\mathrm{F}(1,22)=4.53$, $\mathrm{p}=0.05$ ). Male infants had higher birthweights and larger head circumference and head length measures than females. Three-way ANOVA tests (DA exposure, delivery type and sex of infant) could not be performed due to the low number of infants $(\mathrm{N}=1)$ in one of the cells. 
Newborn Health Status (Apgar) and Screening for Congenital Defects: No congenital defects were observed in newborns. The initial Apgar evaluations were performed at the first possible time following delivery, which ranged from 5 to 30 minutes. Follow up evaluations were performed at $\sim 1$ hour after birth. Apgar scores ranged from 6 to the maximum score of 12 (see Table 9). Again, preliminary two-way ANOVAs were run to examine whether or not the gestation length impacted Apgar scores. The results of these analyses did not indicate a significant main effect of gestation length or DA exposure for either of the Apgar tests ( $p>0.05$, both tests), or an interaction of gestation length and DA exposure ( $>>0.10$, all tests). Two-way ANOVAs were also run to examine the effects of delivery type (C-section and vaginal deliveries) on the Apgar scores. The results of these analyses did not indicate a significant main effect of delivery type or DA exposure for either of the Apgar tests ( $p>0.10$, all tests), or an interaction of DA exposure and delivery type ( $>0.10$, all tests). There was, however, a significant main effects of delivery type on the initial Apgar scores $(\mathrm{F}(1,21)=41.39, \mathrm{p}<0.01)$ but not the second Apgar scores $(\mathrm{F}(1,21)=$ 3.09, $\mathrm{p}=0.09$ ). Apgar scores were lower for $\mathrm{C}$-section delivered newborns at both tests. Results of two-way ANOVA tests examining the effects of sex of the infant on Apgar scores did not indicate a significant main effect of sex of the infant or DA exposure for either of the Apgar tests ( $p>0.10$, all tests), or an interaction of DA exposure and sex of the infant ( $p>0.10$, all tests).

Newborn Plasma DA Concentrations: DA was not detected in the plasma of control females or their offspring at delivery. Plasma DA concentrations at delivery for the adult females in the $0.075 \mathrm{mg} / \mathrm{kg} / \mathrm{day}$ DA exposure group ranged from $0.24 \mathrm{ng} / \mathrm{ml}$ to $4.50 \mathrm{ng} / \mathrm{ml}$. For the adult females in the $0.15 \mathrm{mg} / \mathrm{kg} /$ day group, concentrations ranged from $0.74 \mathrm{ng} / \mathrm{ml}$ to $5.77 \mathrm{ng} / \mathrm{ml}$. Newborn plasma DA concentrations ranged from $0.24 \mathrm{ng} / \mathrm{ml}$ to $0.99 \mathrm{ng} / \mathrm{ml}$ for the $0.075 \mathrm{mg} / \mathrm{kg} /$ day DA exposure group and $0.31 \mathrm{ng} / \mathrm{ml}$ to $3.19 \mathrm{ng} / \mathrm{ml}$ for the 0.15 $\mathrm{mg} / \mathrm{kg} /$ day group (see Table 10). Some of the variability in the plasma DA concentrations is most likely due to the variation in the time between the blood draw and the last maternal dose, which ranged from $\sim 3$ to 27 hours for the females and $\sim 4$ to 27 hours for the newborns (see Table 10). The results of ANOVA tests indicated both maternal and newborn plasma DA concentrations varied with the timing of the post-delivery blood draw (maternal, $F(1,17)=$ 8.40, $\mathrm{p}=0.01$; newborn, $\mathrm{F}(1,16)=8.32, \mathrm{p}=0.01$ ). Analysis of co-variance (ANCOVA) tests examining the effects of delivery type (C-section and vaginal deliveries) did not indicate significant effect of this variable on maternal plasma DA concentrations. A follow-up oneway ANCOVA examining the differences in maternal plasma DA concentrations by DA exposure group did not indicate a significant difference between the groups $(F(1,16)=2.48$, $\mathrm{p}=0.14$ ), after taking into account the timing of the blood draw. ANCOVA tests examining the effects of delivery type or sex of the newborn did not indicate significant effects of these variables on newborn plasma DA concentrations. The results of a one-way ANCOVA, however, did indicate that newborn plasma DA concentrations were significantly higher for the $0.15 \mathrm{mg} / \mathrm{kg} /$ day DA exposure group compared to the $0.075 \mathrm{mg} / \mathrm{kg} /$ day DA exposure group $(\mathrm{F}(1,15)=8.49, \mathrm{p}=0.01)$, after taking into account the timing of the blood draw. Finally, an ANCOVA comparing the plasma DA concentrations of the mother versus and newborn indicated that newborn plasma DA concentrations were significantly lower than maternal concentrations for both DA exposure groups $(F(1,32)=7.63$, $\mathrm{p}<0.01)$, 


\subsection{Discussion}

This study represents the first scientific effort to chart the reproductive and developmental toxicity of DA in a nonhuman primate model. Although data are available from reports of high-level, acute DA poisoning, very little is known about the biological and behavioral effects of low level, chronic oral DA intake. The study was designed to model environmentally relevant exposure scenarios and focused on the translational value of the preclinical primate model for the protection of human health. Previous reports of DA exposure and effects in humans have relied on consumption measures to estimate exposure since biomarkers of DA were not readily available (Boushey et al., 2016, Grattan et al., 2016, 2018). Thus, little is known regarding the toxicokinetics and resulting body burden of DA following chronic, low-level DA exposure in humans. DA concentrations in the current study were dose-dependent, with significantly higher plasma DA levels in the 0.15 $\mathrm{mg} / \mathrm{kg} /$ day DA exposure group compared to the $0.075 \mathrm{mg} / \mathrm{kg} /$ day group. The results also indicate that, while plasma DA concentrations vary during long-term exposure, there is no evidence of consistent increases in DA levels with prolonged exposure. The DA concentrations documented in this cohort are consistent with data from our previous primate studies in non-pregnant animals that demonstrated flip-flop kinetics (DA clearance is limited by a slow absorption rate) and a relatively long apparent plasma half-life for DA (Jing et al., 2018) The high inter-individual variability observed in our prior studies was also replicated in this larger study with pregnant animals. DA concentrations at 5 hours after dosing were lower during pregnancy in our $0.15 \mathrm{mg} / \mathrm{kg} / \mathrm{day}$ DA exposure group. This may have been due to the decision to dose females at their pre-pregnant weight, although pregnancy mediated changes in DA kinetics (altered absorption or clearance) cannot be ruled out. DA was consistently detected in all newborns in the study. The data, however, do not suggest disproportionate accumulation of DA in the newborn after chronic DA exposure. Newborn plasma DA concentrations were consistently lower than those in the dams, suggesting some protective barrier in the placenta that should be identified and characterized. Whether a similar barrier exist in humans is unknown.

Reports of DA toxicity from human poisonings as well as recent epidemiologic studies of coastal communities exposed to DA via dietary intake of shellfish have not investigated reproductive parameters. Our study is the first to pursue these outcomes in a nonhuman primate model. Results from the current study indicate that DA exposure is not associated with female reproductive toxicity; parameters such as the length of the menstrual cycle, the ability to conceive, or the ability to deliver full-term, healthy newborn infants were not compromised in DA exposed females. Studies using rodent models have examined the effects of DA exposure during pregnancy on reproductive success (Levin et al., 2005; Shiotani et al., 2017; Tanemura et al., 2009). The results of these studies also indicate that DA is not a reproductive toxin. In both mouse and rat models of in utero exposure, maternal parameters, such as weight gain during pregnancy and litter size, were unaffected. Wildlife studies of feral sea lions, however, have reported increases in abortions and stillbirth in DA exposed animals and reproductive toxicity is a hallmark of a clinical diagnosis of DA toxicosis in these animals (Goldstein et al., 2009). 
While the current study did not provide evidence of reproductive toxicity due to chronic, low-level DA exposure, the results did indicate the presence of subtle neurological effects in the form of intentional tremors in the adult females. Intentional tremors were observed when females were extending their arms to actively reach for and pick up a food reward from the hand of one of the research staff. The research staff were reliably trained to detect the presence or absence of these tremors during standardized testing sessions throughout the project. The tremors observed were evident only when females were performing the reaching and pick-up task; no tremors were observed during general observations of females in their cages. One control female exhibited tremors throughout the study; with tremors observed on nearly $70 \%$ of the total test sessions. In DA-exposed subjects, there were significant individual differences in the expression of this treatment effect. For the 0.075 $\mathrm{mg} / \mathrm{kg} /$ day DA exposure group, 5 of the 10 females rarely exhibited tremors ( $2 \%$ to $15 \%$ ), while the remaining 5 exhibited tremors on $25 \%$ to $35 \%$ of test sessions. For the 0.15 $\mathrm{mg} / \mathrm{kg} /$ day DA exposure group, 5 of the 11 females rarely exhibited tremors ( $1 \%$ to $14 \%$ ), while 4 females exhibited tremors on $50 \%$ to $80 \%$ of test sessions. We were able to secure supplement funding based on the observations of tremors in our adult females for further evaluation of a subset of animals using magnetic resonance imaging (MRI). In a single, sedated scan, we captured T1- and T2-weighted images, diffusion weighted images, and magnetic resonance spectroscopy data. Systematic inspection of all T2-weighted images by MRI experts in the Department of Radiology revealed that the high tremoring control female had a lesion in the temporal lobe. Thus, we have provided the results of our tremor analysis with and without this female. Detailed results of all aspects of the MRI studies have been summarized in a separate manuscript currently under review.

Wildlife studies of sea lions and studies using rodent and nonhuman primate animal models have reported signs of neurological injury in DA exposed adults. Studies of feral sea lions have reported pacing, ataxia, head weaving and spontaneous recurrent seizures in animals exhibiting DA toxicosis (Cook et al., 2011; Goldstein et al., 2008; Gulland et al., 2002; Scholin et al., 2000). Studies of rodent models have reported persistent neurological injury after DA exposure that is expressed through spontaneous recurrent seizures and epileptic disease (Muha and Ramsdell, 2011; Tiedeken and Ramsdell, 2013). In the rat model, a single IP dose of 4.0 or $7.5 \mathrm{mg} / \mathrm{kg}$ DA resulted in generalized tremors, wet-dog shakes, praying posture (anterior part of body raised with front paws clasped) and loss of postural control (Tryphonas et al., 1990c). These high doses ultimately produced status epilepticus and post mortem histopathology showed selective encephalopathy, neuronal degeneration and vacuolation of the neuropil in the limbic (hippocampus, amygdala) and olfactory systems. In the preclinical nonhuman primate model, evidence of DA-induced tremors has been observed in past investigations but only in animals exhibiting DA toxicosis after IV and IP (non-oral) routes of exposure. In macaque monkeys, a single IV dose at $1.0 \mathrm{mg} / \mathrm{kg}$ and above $(4.0 \mathrm{mg} / \mathrm{kg})$ resulted in tremors and death in $4 / 7$ animals (Scallet et al., 1993). Similarly, Tryphonas and colleagues explored IV and IP DA exposure in macaques and found that single DA doses above $0.5 \mathrm{mg} / \mathrm{kg}$ IV and $4.0 \mathrm{mg} / \mathrm{kg}$ IP produced tremors, rigidity of movement and loss of balance (Tryphonas et al., 1990a). Lesions consisting of vacuolation of the neuropil, astrocytic swelling, and neuronal shrinkage and hyperchromasia were detected in the area postrema, hypothalamus, hippocampus and inner layers of the 
retina. In contrast to IV and IP routes of exposure, past studies of oral dosing of up to 10 $\mathrm{mg} / \mathrm{kg}$ DA have not reported tremors in exposed primate subjects (Truelove et al., 1997; Tryphonas et al., 1990c). While these doses are over 10 times higher than those employed in the present study, the studies did not include standard observations of animals to detect the presence of intentional tremors. These subtle neurological effects, therefore, would have likely gone unnoticed.

Recent results from the epidemiological CoASTAL cohort study in Washington State demonstrate that chronic DA exposure (as measured by the consumption of razor clams) is associated with decrements in memory that are serious enough to affect everyday living skills (Grattan et al., 2018, 2016a). This striking research finding suggests that chronic exposure to low-level DA from harvested shellfish is not without risk to the adult central nervous system. The current study was initiated prior to the publication of the results from the CoASTAL study and focused on evaluating the physical, social and cognitive effects of prenatal DA exposure on the offspring. Assessments of cognition and memory were not included in the study for the DA exposed adult females. Thus, we cannot say at this time whether the tremors represent the sole neurobehavioral effect due to the chronic, low-level DA exposure.

The present study is the first to address fetal DA exposure and birth outcomes in a nonhuman primate model. Consistent with past research in other species, DA did not act as a classic teratogen and newborns were free from physical malformations (Levin et al., 2005; Shiotani et al., 2017). There were no exposure-related differences on birth characteristics, but species-typical sex effects on birthweight and head size (males infants were heavier and larger) were observed. An adaptation of the human newborn Apgar assessment was used to evaluate the health of the newborns and no DA related effects were observed. As anticipated, C-sectioned newborns exhibited lower Apgar scores than newborns from natural deliveries (Yeekian et al., 2013). C-sectioned newborns typically exhibited poorer muscle tone and color and were less active than newborns delivered naturally. These effects, however, were short-lived and scores tended to normalize by the $2^{\text {nd }}$ Apgar test approximately 1 hour after delivery. The ultimate goal of the current study, however, is to evaluate the physical and neurobehavioral development of the DA and control offspring. The cohort of infants in this study are currently being evaluated on a targeted series of neurobehavioral and electroencephalogram (EEG) assessments to study the effects of in utero DA exposure on postnatal development. Past studies using rodent models have reported a constellation of effects following prenatal DA exposure that suggest a marked fetal sensitivity to DA, characterized by enduring changes in a number of behavioral domains, particularly memory, activity levels, social behavior and emotional reactivity (for reviews see Costa et al., 2010; Doucette and Tasker, 2016; Grant et al., 2010; Lefebvre and Robertson, 2010). A number of studies have reported dose- and gender-related differences in some of these outcomes (Adams et al., 2009; Baron et al., 2013; Burt et al., 2008; Doucette et al., 2007, 2004; Gill et al., 2012; Levin et al., 2006, 2005; Marriott et al., 2014; Ryan et al., 2011; Shiotani et al., 2017; Zuloaga et al., 2016). Overall, findings with the rodent model suggest that early life DA exposure is linked to significant changes in brain structure and function that do not diminish over time. Future reports from the current investigation will provide the first nonhuman primate data on the risks of in-utero exposure to oral DA within environmental 
relevant exposure scenarios and will provide greater scientific resolution on the adequacy of regulatory guidelines to protect the health of high-frequency shellfish consumers and their infants. The current results demonstrate that chronic, low-level exposure to DA is associated with injury to the adult CNS and suggest that current regulatory guidelines designed to protect human health may not be adequate for high-frequency shellfish consumers.

\section{Acknowledgments}

This research was supported by grants from the U.S. National Institutes of Health R01 ES023043, P51 OD010425, HD083091 and NCATS Grant TL1 TR000422 (SS). The authors would like to acknowledge the staff and volunteers of the Infant Primate Research Laboratory and the University of Washington National Primate Research Center for their skilled assistance. In addition, we would like to thank Mr. Steven Ellis for his assistance with data processing and analysis.

\section{References}

Adams AL, Doucette TA, James R, Ryan CL, 2009 Persistent changes in learning and memory in rats following neonatal treatment with domoic acid. Physiol. Behav 96, 505-12. 10.1016/j.physbeh. 2008.11.019 [PubMed: 19146865]

Apgar V, 1953 A proposal for a new method of evaluation of the newborn infant, in: Anesthesia and Analgesia. pp. 1056-1059. 10.1213/ANE.0b013e31829bdc5c

Backer L, Miller M, 2016 Sentinel Animals in a One Health Approach to Harmful Cyanobacterial and Algal Blooms. Vet. Sci 3, 8 10.3390/vetsci3020008 [PubMed: 27152315]

Baron AW, Rushton SP, Rens N, Morris CM, Blain PG, Judge SJ, 2013 Sex differences in effects of low level domoic acid exposure. Neurotoxicology 34, 1-8. 10.1016/j.neuro.2012.10.010 [PubMed: 23099319]

Bates SS, Bird CJ, de Freitas ASW, Foxall R, Gilgan M, Hanic L, Johnson GR, McCulloch AW, Odense P, Pocklington R, Quilliam MA, Sim G, Smith JC, Subba Rao DV, Todd ECD, Walter JA, Wright JLC, 1989 Pennate Diatom Nitzschia pungens as the Primary Source of Domoic Acid, a Toxin in Shellfish from Eastern Prince Edward Island, Canada. Can. J. Fish Aquat. Sci 46, 12031215.

Berdalet E, Fleming LE, Gowen R, Davidson K, Hess P, Backer LC, Moore SK, Hoagland P, Enevoldsen H, 2016 Marine harmful algal blooms, human health and wellbeing: Challenges and opportunities in the 21st century. J. Mar. Biol. Assoc. United Kingdom 96, 61-91. 10.1017/ S0025315415001733

Bossart GD, 2011 Marine mammals as sentinel species for oceans and human health. Vet. Pathol 48, 676-690. 10.5670/oceanog.2006.77 [PubMed: 21160025]

Boushey CJ, Delp EJ, Ahmad Z, Wang Y, Roberts SM, Grattan L, 2016 Dietary assessment of domoic acid exposure: What can be learned from traditional methods and new applications for a technology assisted device. Harmful Algae 57, 51-55. 10.1016/j.hal.2016.03.013

Burbacher T, Shen D, Grant K, Sheppard L, Damian D, Ellis S, Liberato N, 1999 Reproductive and offspring developmental effects following maternal inhalation exposure to methanol in nonhuman primates. Res. Rep. Health. Eff. Inst i-ii, 1-117;

Burbacher TM, Grant KS, Shen DD, Sheppard L, Damian D, Ellis S, Liberato N, 2004 Chronic maternal methanol inhalation in nonhuman primates (Macaca fascicularis): Reproductive performance and birth outcome. Neurotoxicol. Teratol 26, 639-650. 10.1016/j.ntt.2004.06.001 [PubMed: 15315813]

Burbacher TM, Mohamed MK, Mottett NK, 1988 Methylmercury effects on reproduction and offspring size at birth. Reprod. Toxicol 1, 267-78.

Burt MA, Ryan CL, Doucette TA, 2008 Altered responses to novelty and drug reinforcement in adult rats treated neonatally with domoic acid. Physiol. Behav 93, 327-336. 10.1016/j.physbeh. 2007.09.003 [PubMed: 17980392] 
Buse E, Habermann G, Osterburg I, Korte R, Weinbauer GF, 2003 Reproductive/developmental toxicity and immunotoxicity assessment in the nonhuman primate model. Toxicology 185, 221227. 10.1016/S0300-483X(02)00614-5 [PubMed: 12581697]

Carter AM, 2007 Animal Models of Human Placentation - A Review. Placenta 28 10.1016/j.placenta. 2006.11.002

Centers for Disease Control and Prevention, 2017 Harmful Algal Bloom (HAB)-Associated Illness. URL https://www.cdc.gov/habs/general.html (accessed September 28, 2018).

Cook P, Reichmuth C, Gulland F, 2011 Rapid behavioural diagnosis of domoic acid toxicosis in California sea lions. Biol. Lett 7, 536-538. 10.1098/rsbl.2011.0127 [PubMed: 21389016]

Costa LG, Giordano G, Faustman EM, 2010 Domoic acid as a developmental neurotoxin. Neurotoxicology 31, 409-423. 10.1016/j.neuro.2010.05.003 [PubMed: 20471419]

Dakshinamurti K, Sharma SK, Sundaram M, Watanabe T, 1993 Hippocampal changes in developing postnatal mice following intrauterine exposure to domoic acid. J. Neurosci 13, 4486-4495. [PubMed: 8105041]

Doucette TA, Bernard PB, Husum H, Perry MA, Ryan CL, Tasker RA, 2004 Low doses of domoic acid during postnatal development produce permanent changes in rat behaviour and hippocampal morphology. Neurotox. Res 6, 555-563. 10.1007/BF03033451 [PubMed: 15639787]

Doucette TA, Ryan CL, Tasker RA, 2007 Gender-based changes in cognition and emotionality in a new rat model of epilepsy. Amino Acids 32, 317-322. 10.1007/s00726-006-0418-7 [PubMed: 17068662]

Doucette TA, Tasker RA, 2016 Perinatal domoic acid as a neuroteratogen, in: Current Topics in Behavioral Neurosciences. Springer, Cham, pp. 87-110. 10.1007/7854_2015_417

Ferriss BE, Marcinek DJ, Ayres D, Borchert J, Lefebvre KA, 2017 Acute and chronic dietary exposure to domoic acid in recreational harvesters: A survey of shellfish consumption behavior. Environ. Int 101, 70-79. 10.1016/j.envint.2017.01.006 [PubMed: 28109640]

Fialkowski MK, McCrory MA, Roberts SM, Tracy JK, Grattan L, Boushey CJ, 2010 Evaluation of Dietary Assessment Tools Used to Assess the Diet of Adults Participating in the Communities Advancing the Studies of Tribal Nations Across the Lifespan Cohort. J. Am. Diet. Assoc 110, 6573. 10.1016/j.jada.2009.10.012 [PubMed: 20102829]

Garrison DL, Conrad SM, Eilers PP, Waldron EM, 1992 Confirmation of Domoic Acid Production By Pseudonitzschia-Australis (Bacillariophyceae) Cultures. J. Phycol 28, 604-607. 10.1111/j. 0022-3646.1992.00604.x

Gill DA, Perry MA, McGuire EP, Pérez-Gómez A, Tasker RA, 2012 Low-dose neonatal domoic acid causes persistent changes in behavioural and molecular indicators of stress response in rats. Behav. Brain Res 230, 409-417. 10.1016/j.bbr.2012.02.036 [PubMed: 22387806]

Goldstein T, Mazet JK, Zabka TS, Langlois G, Colegrove KM, Silver M, Bargu S, Van Dolah FM, Conrad P. a, Barakos J, Williams DC, Dennison S, Haulena M, 2008 Novel symptomatology and changing epidemiology of domoic acid toxicosis in California sea lions (Zalophus californianus): an increasing risk to marine mammal health. Proc. R. Soc 275, 267-276. 10.1098/rspb.2007.1221

Goldstein T, Zabka TS, Delong R, Wheeler EA, Ylitalo G, Bargu S, Silver M, Leighfield T, Van Dolah FM, Langlois G, Sidor I, Dunn JL, Gulland FM, 2009 The Role of Domoic Acid in Abortion and Premature Parturition of California Sea Lions (Zalophus Californianus) on San Miguel Island, California. J. Wildl. Dis 45, 91-108. [PubMed: 19204339]

Grant KS, Burbacher TM, Faustman EM, Grattan L, 2010 Domoic acid: Neurobehavioral consequences of exposure to a prevalent marine biotoxin. Neurotoxicol. Teratol 32, 132-141. 10.1016/j.ntt.2009.09.005 [PubMed: 19799996]

Grattan L, Boushey CJ, Liang Y, Lefebvre KA, Castellon LJ, Roberts KA, Toben AC, Morris JGJ, Jr., 2018 Repeated Dietary Exposure to Low Levels of Domoic Acid and Problems with Everyday Memory: Research to Public Health Outreach. Toxins (Basel). 10, 103 10.3390/toxins10030103

Grattan L, Boushey CJ, Tracy K, Trainer VL, Roberts SM, Schluterman N, Morris JGJ, Jr., Schulterman N, Morris JGJ, 2016a The association between razor clam consumption and memory in the CoASTAL cohort. Harmful Algae 57, 20-25. 10.1016/j.hal.2016.03.011

Grattan L, Holobaugh S, Morris JGJ, 2016b Harmful algal blooms and public health. Harmful Algae. 10.1016/j.hal.2016.05.003 
Gulland FMD, Haulena M, Fauquier D, Langlois G, Lander ME, Zabka TS, Duerr R, 2002 Domoic acid toxicity in Californian sea lions (Zalophus californianus): clinical signs. Vet. Rec 150, 475480. 10.1136/vr.150.15.475 [PubMed: 11995679]

Jeffery B, Barlow T, Moizer K, Paul S, Boyle C, 2004 Amnesic shellfish poison. Food Chem. Toxicol 42, 545-557. 10.1016/j.fct.2003.11.010 [PubMed: 15019178]

Jing J, Petroff R, Shum S, Crouthamel B, Topletz AR, Grant KS, Burbacher TM, Isoherranen N, 2018 Toxicokinetics and physiologically based pharmacokinetic modeling of the shellfish toxin domoic acid in nonhuman primates. Drug Metab. Dispos 46, 155-165. 10.1124/dmd.117.078485 [PubMed: 29150543]

King BF, 1993 Development and structure of the placenta and fetal membranes of nonhuman primates. J. Exp. Zool 266, 528-540. 10.1002/jez.1402660605 [PubMed: 8371096]

Kirkley KS, Madl JE, Duncan C, Gulland FM, Tjalkens RB, 2014 Domoic acid-induced seizures in California sea lions (Zalophus californianus) are associated with neuroinflammatory brain injury. Aquat. Toxicol 156, 259-268. 10.1016/j.aquatox.2014.09.003 [PubMed: 25286249]

Lefebvre KA, Bargu S, Kieckhefer T, Silver MW, 2002 From sandabs to blue whales: the pervasiveness of domoic acid. Toxicon 40, 971-977. [PubMed: 12076651]

Lefebvre KA, Kendrick PS, Ladiges W, Hiolski EM, Ferriss BE, Smith DR, Marcinek DJ, 2017 Chronic low-level exposure to the common seafood toxin domoic acid causes cognitive deficits in mice. Harmful Algae 64, 20-29. 10.1016/j.hal.2017.03.003 [PubMed: 28427569]

Lefebvre KA, Quakenbush L, Frame E, Huntington KB, Sheffield G, Stimmelmayr R, Bryan A, Kendrick P, Ziel H, Goldstein T, Snyder JA, Gelatt T, Gulland FMD, Dickerson B, Gill V, 2016 Prevalence of algal toxins in Alaskan marine mammals foraging in a changing arctic and subarctic environment. Harmful Algae 55, 13-24. 10.1016/j.hal.2016.01.007 [PubMed: 28073526]

Lefebvre KA, Robertson A, 2010 Domoic acid and human exposure risks: A review. Toxicon 56, 218 230. 10.1016/j.toxicon.2009.05.034 [PubMed: 19505488]

Levin ED, Pang WG, Harrison J, Williams P, Petro A, Ramsdell JS, 2006 Persistent neurobehavioral effects of early postnatal domoic acid exposure in rats. Neurotoxicol. Teratol 28, 673-680. 10.1016/j.ntt.2006.08.005 [PubMed: 17046199]

Levin ED, Pizarro K, Pang WG, Harrison J, Ramsdell JS, 2005 Persisting behavioral consequences of prenatal domoic acid exposure in rats. Neurotoxicol. Teratol 27, 719-725. 10.1016/j.ntt. 2005.06.017 [PubMed: 16054336]

Mariën K, 1996 Establishing tolerable dungeness crab (Cancer magister) and razor clam (Siliqua patula) domoic acid contaminant levels. Environ. Health Perspect 104, 1230-6. [PubMed: 8959413]

Marriott AL, Tasker RA, Ryan CL, Doucette TA, 2014 Neonatal domoic acid abolishes latent inhibition in male but not female rats and has differential interactions with social isolation. Neurosci. Lett 578, 22-26. 10.1016/j.neulet.2014.06.025 [PubMed: 24954074]

McCabe RM, Hickey BM, Kudela RM, Lefebvre KA, Adams NG, Bill BD, Gulland FMDD, Thomson RE, Cochlan WP, Trainer VL, 2016 An unprecedented coastwide toxic algal bloom linked to anomalous ocean conditions. Geophys. Res. Lett. 43, 10,366-10,376. 10.1002/2016GL070023

Mckibben SM, Peterson W, Wood AM, Trainer VL, Hunter M, White AE, 2017 Climatic regulation of the neurotoxin domoic acid. Proc. Natl. Acad. Sci 114, 239-244. 10.1073/pnas.1606798114 [PubMed: 28069959]

Montie EW, Wheeler E, Pussini N, Battey TWK, Barakos J, Dennison S, Colegrove K, Gulland F, 2010 Magnetic resonance imaging quality and volumes of brain structures from live and postmortem imaging of California sea lions with clinical signs of domoic acid toxicosis. Dis. Aquat. Organ 91, 243-256. 10.3354/dao02259 [PubMed: 21133324]

Muha N, Ramsdell JS, 2011 Domoic acid induced seizures progress to a chronic state of epilepsy in rats. Toxicon 57, 168-171. 10.1016/j.toxicon.2010.07.018 [PubMed: 20688097]

Naiken S, Griffiths M-A, Edouard L, Padayatchy N, 2015 Factors influencing reproduction in captivebred cynomolgus monkeys (Macaca fascicularis) from Mauritius. Am. J. Primatol 77, 1290-1298. 10.1002/ajp.22482 [PubMed: 26375598] 
NOAA, 2014 What percentage of the American Population Lives near the Coast? Web. Natl. Ocean Serv URL: https://www.oceanservice.noaa.gov/facts/population.html\%0Ahttp:// oceanservice.noa.gov/facts/population.html (accessed December 14, 2018).

Perl TM, Bedard L, Kosatsky T, Hockin J, Todd ECD, Remis R, 1990a An Outbreak of Toxic Encephalopathy Caused by Eating Mussels Contaminated with Domoic Acid. N. Engl. J. Med 322, 1775-1780. [PubMed: 1971709]

Perl TM, Bedard L, Kosatsky T, Hockin JC, Todd EC, McNutt LA, Remis RS, 1990b Amnesic shellfish poisoning: a new clinical syndrome due to domoic acid. Canada Dis. Wkly. Rep 16 Suppl 1, 7-8.

Ramsdell JS, Gulland FM, 2014 Domoic acid epileptic disease. Mar. Drugs 12, 1185-1207. 10.3390/ md12031185 [PubMed: 24663110]

Ryan CL, Robbins M. a, Smith M, Gallant IC, Adams-Marriott AL, Doucette TA, 2011 Altered social interaction in adult rats following neonatal treatment with domoic acid. Physiol. Behav 102, 291295. 10.1016/j.physbeh.2010.11.020 [PubMed: 21108956]

Scallet A, Kowalke PK, Rountree RL, Thorn BT, Binienda ZK, 2004 Electroencephalographic, behavioral, and c-fos responses to acute domoic acid exposure. Neurotoxicol. Teratol 26, 331-342. 10.1016/j.ntt.2003.10.004 [PubMed: 15019966]

Scallet AC, Binienda ZK, Caputo FAA, Hall S, Paule MGGMG, Rountree RL, Schmued LC, Sobotka TJ, Slikker W, 1993 Domoic acid-treated cynomolgus monkeys (M. fascicularis): Effects of Dose on Hippocampal Neuronal and Terminal Degeneration. Brain Res. 627, 307-313. 10.1016/0006-8993(93)90335-K [PubMed: 8298975]

Scholin CA, Gulland FMD, Doucette GJ, Benson S, Busman M, Chavez FP, Cordaro J, DeLong R, De Vogelaere A, Harvey J, Haulena M, Lefebvre KA, Lipscomb T, Loscutoff S, Lowenstine LJ, Marin R, Miller PE, McLellan WA, Moeller PDR, Powell CL, Rowles TTK, Silvagni P, Silver MW, Spraker T, Trainer VL, Van Dolah FM, 2000 Mortality of sea lions along the central California coast linked to a toxic diatom bloom. Nature 403, 80-84. 10.1038/47481 [PubMed: 10638756]

Shiotani M, Cole TB, Hong S, Park JJY, Griffith WC, Burbacher TM, Workman T, Costa LG, Faustman EM, 2017 Neurobehavioral assessment of mice following repeated oral exposures to domoic acid during prenatal development. Neurotoxicol. Teratol 64, 8-19. 10.1016/J.NTT. 2017.09.002 [PubMed: 28916171]

Shum S, Kirkwood JS, Jing J, Petroff R, Crouthamel B, Grant KS, Burbacher TM, Nelson WL, Isoherranen N, 2018 Validated HPLC-MS/MS Method To Quantify Low Levels of Domoic Acid in Plasma and Urine after Subacute Exposure. ACS Omega 3, 12079-12088. 10.1021/acsomega. 8b02115 [PubMed: 30320288]

Stommel EW, Watters MR, 2004 Marine neurotoxins: Ingestible toxins. Curr. Treat. Options Neurol 10.1007/s11940-004-0020-9

Tanemura K, Igarashi K, Matsugami T-R, Aisaki K, Kitajima S, Kanno J, 2009 Intrauterine environment-genome interaction and Children's development (2): Brain structure impairment and behavioral disturbance induced in male mice offspring by a single intraperitoneal administration of domoic acid (DA) to their dams. J. Toxicol. Sci 34, SP279-SP286. 10.2131/jts.34.SP279 [PubMed: 19571481]

Teitelbaum J, Zatorre RJ, Carpenter S, Gendron D, Cashman NR, 1990a Neurological Sequelae of Domoic Acid Intoxication. Symp. Domoic Acid Toxic. 16, 9-12. $10.2174 / 13816128236661701241$

Teitelbaum J, Zatorre RJ, Carpenter S, Gendron D, Evans A, Gjedde A, Cashman N, 1990b Neurologic Sequelae of Domoic Acid Intoxication due to the Ingestion of Contaminated Mussels. N. Engl. J. Med 322, 1781-1787. [PubMed: 1971710]

Thompson BL, Levitt P, Stanwood GD, 2009 Prenatal exposure to drugs: effects on brain development and Implications for Policy and Education. Nat. Rev. Neurosci 10, 303-312. 10.1038/ nrn2598.Prenatal [PubMed: 19277053]

Tiedeken JA, Ramsdell JS, 2013 Persistent neurological damage associated with spontaneous recurrent seizures and atypical aggressive behavior of domoic acid epileptic disease. Toxicol. Sci 133, 133143. 10.1093/toxsci/kft037 [PubMed: 23457124] 
Toyofuku H, 2006 Joint FAO/WHO/IOC activities to provide scientific advice on marine biotoxins (research report). Mar. Pollut. Bull 52, 1735-1745. 10.1016/j.marpolbul.2006.07.007 [PubMed: 16979668]

Truelove J, Mueller R, Pulido O, Martin L, Fernie S, Iverson F, 1997 30-day oral toxicity study of domoic acid in cynomolgus monkeys: Lack of overt toxicity at doses approaching the acute toxic dose. Nat. Toxins 5, 111-114. 10.1002/nt.5 [PubMed: 9285915]

Tryphonas L, Truelove J, Iverson F, 1990a Acute parenteral neurotoxicity of domoic acid in cynomolgus monkeys (M. fascicularis). Toxicol. Pathol 18, 297-303. 10.1177/019262339001800208 [PubMed: 2268382]

Tryphonas L, Truelove J, Iverson F, Todd ECD, Nera E, 1990b Neuropathology of Experimental Domoic Acid Poisoning in Nonhuman Primates and Rats. Symp. Domoic Acid Toxic. 78-81.

Tryphonas L, Truelove J, Nera E, Iverson F, 1990c Acute Neurotoxicity of Domoic Acid in the Rat. Toxicol. Pathol 18, 1-9. 10.1177/019262339001800101 [PubMed: 2362984]

Tryphonas L, Truelove J, Todd ECD, Nera E, Iverson F, 1990d Experimental oral toxicity of domoic acid in cynomolgus monkeys (Macaca fascicularis) and rats. Food Chem. Toxicol 28, 707-715. 10.1016/0278-6915(90)90147-F [PubMed: 2276699]

Wells ML, Trainer VL, Smayda TJ, Karlson BSO, Trick CG, Kudela RM, Ishikawa A, Bernard S, Wulff A, Anderson DM, Cochlan WP, 2015 Harmful algal blooms and climate change: Learning from the past and present to forecast the future. Harmful Algae 49, 68-93. 10.1016/j.hal. 2015.07.009 [PubMed: 27011761]

Xi D, Peng YG, Ramsdell JS, 1997 Domoic acid is a potent neurotoxin to neonatal rats. Nat. Toxins 5, 74-79. 10.1002/(SICI)(1997)5:2\&lt;74::AID-NT4\&gt;3.0.CO;2-I [PubMed: 9131593]

Yeekian C, Jesadapornchai S, Urairong K, Santibenjakul S, Suksong W, Nuchprayoon C, 2013 Comparison of maternal factors and neonatal outcomes between elective cesarean section and spontaneous vaginal delivery. J. Med. Assoc. Thail 96, 389-394.

Zhu Z, Qu P, Fu F, Tennenbaum N, Tatters AO, Hutchins DA, 2017. Understanding the blob bloom: Warming increases toxicity and abundance of the harmful bloom diatom Pseudo-nitzschia in California coastal waters. Harmful Algae 67, 36-43. 10.1016/j.hal.2017.06.004 [PubMed: 28755719]

Zuloaga DGG, Lahvis GPP, Mills B, Pearce HLL, Turner J, Raber J, 2016 Fetal domoic acid exposure affects lateral amygdala neurons, diminishes social investigation and alters sensory-motor gating. Neurotoxicology 53, 132-140. 10.1016/j.neuro.2016.01.007 [PubMed: 26797589] 


\section{Highlights}

1. Domoic acid acts as a tremoragen after chronic, low-dose oral exposure in adults.

2. Exposure across pregnancy does not result in maternal reproductive toxicity.

3. In-utero exposure does not adversely impact physical characteristics of exposed newborns.

4. Current regulatory guidelines may not adequately protect high-frequency shellfish consumers from DA-induced neurological injury. 
Before Pregnancy ${ }^{1}$

$0.075 \mathrm{mg} / \mathrm{kg} / \mathrm{day}(\mathrm{n}=10)$

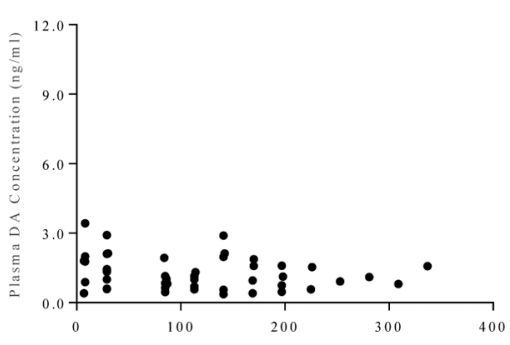

$0.15 \mathrm{mg} / \mathrm{kg} / \mathrm{day}(\mathrm{n}=11)$

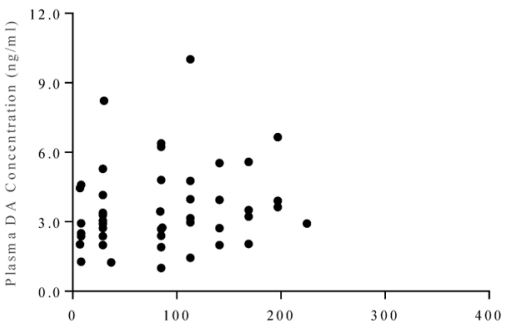

$0.075 \mathrm{mg} / \mathrm{kg} / \mathrm{day}(\mathrm{n}=10)$

24-Hour Post Dose Sample
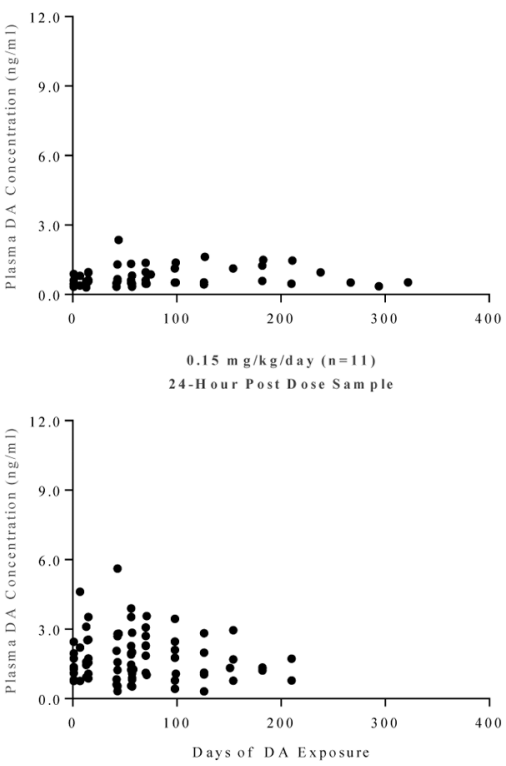

During Pregnancy

$0.075 \mathrm{mg} / \mathrm{kg} / \mathrm{day}(\mathrm{n}=9)$

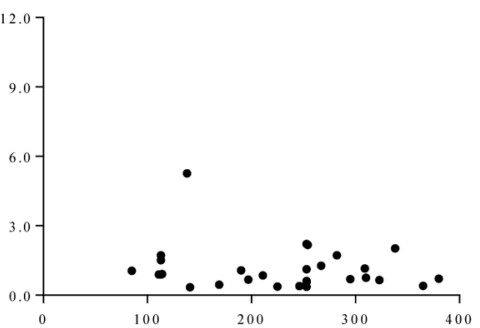

$0.15 \mathrm{mg} / \mathrm{kg} / \mathrm{day}(\mathrm{n}=11)$
5-Hour Post Dose Sample

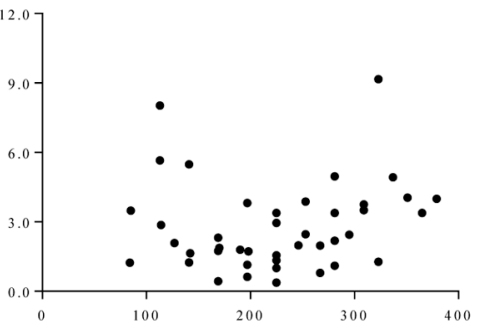

$0.075 \mathrm{mg} / \mathrm{kg} / \mathrm{day}(\mathrm{n}=9)$
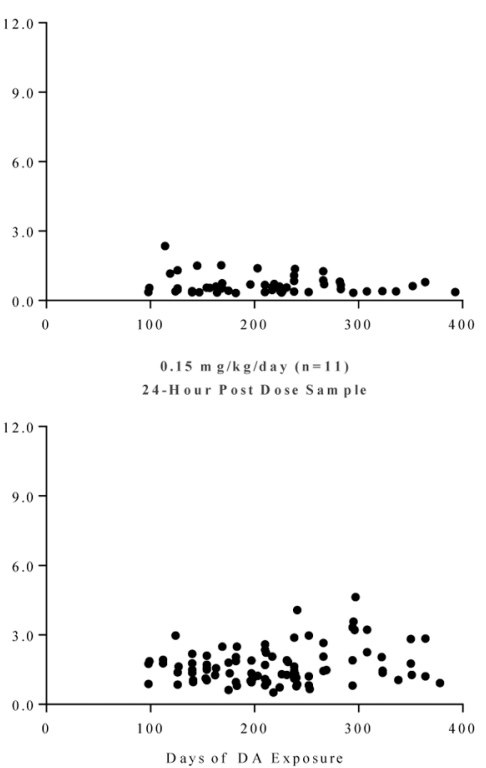

Figure 1. Maternal Plasma DA Concentration (ng/ml) Before and During Pregnancy ${ }^{1}$ End of breeding for females who did not conceive

${ }^{2}$ For $0.075 \mathrm{mg} / \mathrm{kg} /$ day DA exposure group, 69 BLQ samples (35 24-hour samples before pregnancy, 29 24-hour samples during pregnancy and 5 5-hour samples during pregnancy). For $0.15 \mathrm{mg} / \mathrm{kg} / \mathrm{day}$ DA exposure group, 9 BLQ samples (3 -24-hour samples before pregnancy and 6 24-hours samples during pregnancy) 

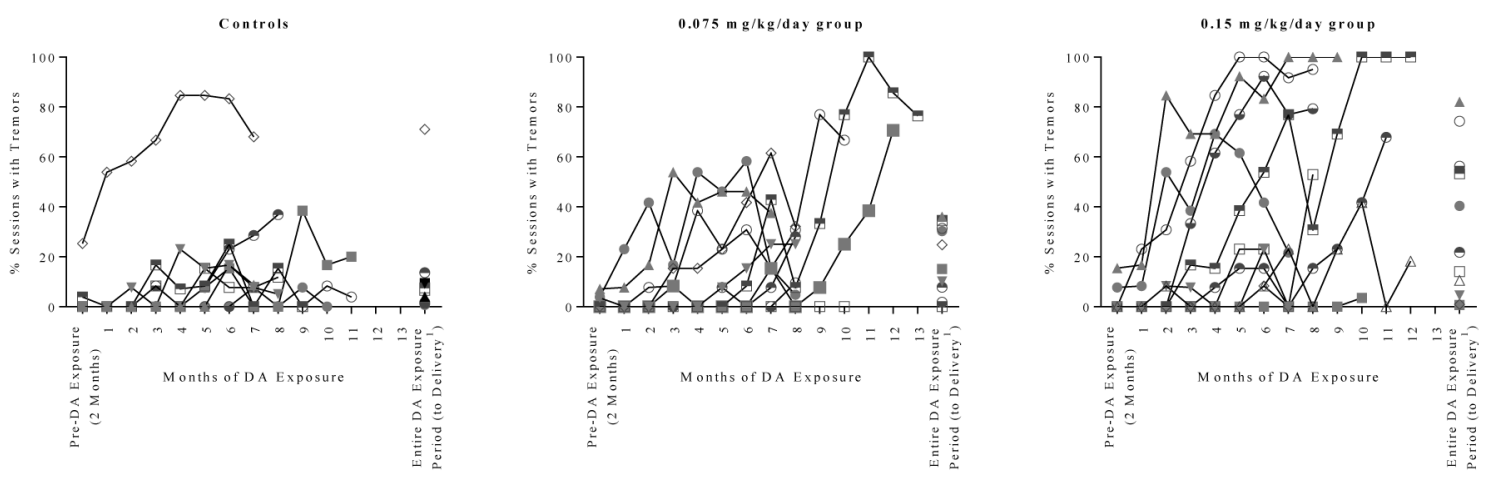

Figure 2: \% of Sessions Arm/Hand Tremors Observed on Reaching Task During 2-Month PreExposure Period, Monthly During DA Exposure Period and Over Entire DA Exposure Period To Delivery 1

${ }^{1}$ End of breeding for females who did not conceive 
Table 1:

Mean \pm SE (Range) \# of Days Exposed to DA at Conception ${ }^{1}$ and Delivery

\begin{tabular}{lll} 
DA Exposure Group & Conception & Delivery \\
\hline Controls $(\mathrm{N}=10)$ & $113 \pm 13(82-194)$ & $274 \pm 14(232-361)$ \\
$0.075 \mathrm{mg} / \mathrm{kg} /$ day $(\mathrm{N}-10)$ & $132 \pm 19(84-233)$ & $294 \pm 19(239-403)$ \\
$0.15 \mathrm{mg} / \mathrm{kg} /$ day $(\mathrm{N}=11)$ & $139 \pm 17(79-232)$ & $298 \pm 18(233-387)$ \\
\hline
\end{tabular}

${ }^{1}$ End of breeding for females who did not conceive

Note: No significant differences between groups in \# of days exposed to DA at conception or delivery 
Table 2:

Mean \pm SE (Range) Maternal Plasma DA Concentrations (ng/ml) Before and During Pregnancy ${ }^{1}$

\begin{tabular}{lllll} 
& \multicolumn{2}{c}{ Before Preanancy } & \multicolumn{2}{c}{ During Preanancy } \\
DA Exposure Group & 5-Hour Sample & 24-Hour Sample & 5-Hour Sample & 24-Hour Sample \\
\hline $0.075 \mathrm{mg} / \mathrm{kg} /$ day $(\mathrm{N}=10)$ & $1.31 \pm 0.18$ & $0.49 \pm 0.07$ & $0.93 \pm 0.22^{3}$ & $0.50 \pm 0.07^{3}$ \\
& $(0.62-2.76)$ & $(0.24-0.98)$ & $(0.46-2.57)$ & $(0.28-1.04)$ \\
& & & $2.93 \pm 0.38$ & $1.50 \pm 0.17$ \\
$0.15 \mathrm{mg} / \mathrm{kg} /$ day $(\mathrm{N}=11)$ & $3.42 \pm 0.35$ & $1.65 \pm 0.21$ & $(0.69-4.69)$ & $(0.55-2.39)$ \\
\hline
\end{tabular}

${ }^{1}$ Mean of individual mean values for each female. For $0.075 \mathrm{mg} / \mathrm{kg} /$ day DA exposure group, mean calculations include 69 BLQ samples (35 24hour samples before pregnancy, 29 24-hour samples during pregnancy and 5 -hour samples during pregnancy). For $0.15 \mathrm{mg} / \mathrm{kg} / \mathrm{day}$ DA exposure group, mean calculations include 9 BLQ samples (3 -24-hour samples before pregnancy and 6 24-hours samples during pregnancy)

2 End of breeding for females who did not conceive

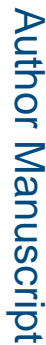

${ }^{3} \mathrm{~N}=9$ during pregnancy

Note: Maternal DA plasma concentrations significantly higher in $0.15 \mathrm{mg} / \mathrm{kg} /$ day DA exposure group prior to and during pregnancy $(\mathrm{p}<0.01$, all tests). 5-Hour Maternal DA plasma concentrations significantly lower during pregnancy $(\mathrm{p}=0.03)$. 
Table 3:

Mean \pm SE (Range) Weights (Kg) of Females Prior to and During DA Exposure and Weight Gain (Kg) during Pregnancy

\begin{tabular}{lcll} 
& No DA Exposure & \multicolumn{2}{c}{ DA Exposure } \\
DA Exposure Group & Pre-DA Exposure Weights & Pre-Pregnancy Weights ${ }^{\mathbf{1}, 2}$ & Pregnancy Weight Gain \\
\hline Controls $(\mathrm{N}=10)$ & $3.50 \pm 0.10(2.98-3.91)$ & $3.63 \pm 0.13(3.08-4.23)$ & $1.72 \pm 0.17(1.16-2.88)^{3}$ \\
$0.075 \mathrm{mg} / \mathrm{kg} /$ day $(\mathrm{N}=10)$ & $3.58 \pm 0.18(2.89-4.77)$ & $3.85 \pm 0.22(3.04-5.05)$ & $1.95 \pm 0.21(1.13-2.97)$ \\
$0.15 \mathrm{mg} / \mathrm{kg} /$ day $(\mathrm{N}=11)$ & $3.64 \pm 0.13(3.05-4.29)$ & $3.86 \pm 0.18(3.19-4.81)$ & $1.62 \pm 0.24(0.35-2.56)^{3}$ \\
\hline
\end{tabular}

14 month pre-DA exposure period, $\sim 3$ to 8 month Pre-Pregnancy period

2 End of breeding for females who did not conceive

${ }^{3} \mathrm{~N}=9$

Note: No significant exposure group differences in weights of females during Pre DA Exposure or Pre-Pregnancy or weight gain of females during pregnancy. 
Table 4:

Mean \pm SE (Range) \% Sessions Arm/Hand Tremors Observed During 2-month Pre-DA exposure period, DA exposure period and "Tremor Increase Scores (\% tremors observed during the DA exposure period ${ }^{1}$ minus the $\%$ tremors observed during the 2 month Pre-DA exposure period).

\begin{tabular}{llll} 
DA Exposure Group & $\underline{\text { Pre-DA Exposure }}$ & DA Exposure $^{1}$ & Tremor Increase Score $^{\text {DAntrols }(\mathrm{N}=10)}$ \\
\hline Con & $3.0 \pm 2.6(0.0-25.9)$ & $12.5 \pm 6.6(0.7-71.0)$ & $9.6 \pm 4.2(0.7-45.1)^{2}$ \\
$0.075 \mathrm{mg} / \mathrm{kg} /$ day $(\mathrm{N}=10)$ & $1.5 \pm 0.8(0.0-7.4)$ & $19.2 \pm 4.4(0.0-36.0)$ & $17.7 \pm 4.1(0.0-34.5)$ \\
$0.15 \mathrm{mg} / \mathrm{kg} /$ day $(\mathrm{N}=11)$ & $2.1 \pm 0.8(0.0-15.4)$ & $32.6 \pm 4.4(0.7-74.3)$ & $30.5 \pm 8.3(0.7-74.3)$ \\
\hline
\end{tabular}

1 Exposure to delivery or end of breeding for females who did not conceive

$$
2
$$

${ }^{2}$ Includes female with brain lesion. Tremor Increase Score without female 5.6 $\pm 1.4 \%$ 
Table 5:

Mean \pm SE (Range) Menstrual Cycle Length Prior to and during DA Exposure

\begin{tabular}{llllll} 
& \multicolumn{2}{l}{ Pre-DA Exposure Cycle Length } & & & \multicolumn{2}{c}{ DA Exposure Cycle Length } \\
DA Exposure Group & Cycle \#1 & Cycle \#2 & & Cycle \#1 & Cycle \#2 \\
\hline Controls (N-10) & $31 \pm 2(25-45)$ & $29 \pm 1(26-37)$ & & $32 \pm 2(24-51)$ & $31 \pm 2(26-41)$ \\
$0.075 \mathrm{mg} / \mathrm{kg} /$ day $(\mathrm{N}=11)$ & $32 \pm 2(26-43)$ & $33 \pm 2(26-42)$ & & $31 \pm 1(26-41)$ & $33 \pm 2(23-52)$ \\
$0.15 \mathrm{mg} / \mathrm{kg} /$ day $(\mathrm{N}=11)$ & $29 \pm 1(21-33)$ & $29 \pm 1(23-38)$ & & $29 \pm 1(24-35)$ & $29 \pm 1(24-32)$ \\
\hline $1_{\text {Length in days }}$ & & & & \\
$2_{\sim 4}$ month Pre-DA exposure period, $\sim 4$ months of DA exposure
\end{tabular}

Note: No significant DA exposure group differences in menstrual cycle lengths of females prior to and during initial DA exposures. 
Table 6:

Mean \pm SE (Range) \# of Breedings to Conception and Rates for Female Reproductive Outcomes

\begin{tabular}{lllll} 
DA Exposure Group & $\begin{array}{l}\text { \# Breeding } \\
\text { to Conception }\end{array}$ & $\begin{array}{l}\text { Conception } \\
\text { Rate }\end{array}$ & $\begin{array}{l}\text { C-Section } \\
\text { Delivery Rate }\end{array}$ & $\begin{array}{l}\text { Liveborn } \\
\text { Delivery Rate }\end{array}$ \\
\hline Controls $(\mathrm{N}=10)$ & $2.1 \pm 0.62(1-7)$ & $90 \%(9 / 10)$ & $56 \%(5 / 9)$ & $100 \%(9 / 9)$ \\
$0.075 \mathrm{mg} / \mathrm{kg} /$ day $(\mathrm{N}=10)$ & $2.2 \pm 0.63(1-7)$ & $90 \%(9 / 10)$ & $67 \%(6 / 9)^{2}$ & $100 \%(9 / 9)$ \\
$0.15 \mathrm{mg} / \mathrm{kg} /$ day $(\mathrm{N}=11)$ & $2.6 \pm 0.54(1-6)$ & $100 \%(11 / 11)$ & $73 \%(8 / 11)^{3}$ & $91 \%(10 / 11)$ \\
\hline
\end{tabular}

Note: No significant DA exposure group differences in number of breedings to conception or conception, C-section delivery or liveborn delivery rates.

${ }^{1} \mathrm{C}$-sections due to unproductive labor $(\mathrm{N}=2)$, excessive vaginal bleeding $(\mathrm{N}=1)$, fetal distress $(\mathrm{N}=1)$, breech presentation $(\mathrm{N}=1)$

${ }^{2}$-sections due to unproductive labor $(\mathrm{N}=3)$, excessive vaginal bleeding $(\mathrm{N}=1)$, fetal distress $(\mathrm{N}=1)$, Placenta Previa $(\mathrm{N}=1)$

${ }^{3}$ C-sections due to unproductive labor $(\mathrm{N}=2)$, excessive vaginal bleeding $(\mathrm{N}=2)$, fetal distress $(\mathrm{N}=1)$, breech presentation $(\mathrm{N}=2)$, Placenta Previa $(\mathrm{N}=1)$ 
Table 7:

Mean \pm SE (Range) Length of Pregnancy (Days)

DA Exposure Group Pregnancy Length (days)

Controls (N=9) 162 $\pm 2.3(151-172)$

$0.075 \mathrm{mg} / \mathrm{kg} / \mathrm{day}(\mathrm{N}=9) \quad 162 \pm 2.3(152-170)$

$0.15 \mathrm{mg} / \mathrm{kg} / \mathrm{day}(\mathrm{N}=11) \quad 160 \pm 2.0(146-170$

Note: No significant DA exposure group differences in length of pregnancy. 
Table 8:

Mean \pm SE (Range) for Infant Birth Characteristics

\begin{tabular}{|c|c|c|c|c|c|}
\hline \multicolumn{6}{|l|}{ Males } \\
\hline & & Crown-Rump & Head & Head & Head \\
\hline DA Exposure Group & Birthweight & Length & & & \\
\hline Controls $(\mathrm{N}=5)$ & $\begin{array}{l}330 \pm 7.2 \\
(310-355)\end{array}$ & $\begin{array}{l}174.2 \pm 3.0 \\
(166.5-181.0)\end{array}$ & $\begin{array}{l}182.0 \pm 1.3 \\
(177.0-184.5)\end{array}$ & $\begin{array}{l}48.6 \pm 0.6 \\
(47.0-50.5)\end{array}$ & $\begin{array}{l}60.6 \pm 0.7 \\
(58.0-62.5)\end{array}$ \\
\hline $0.075 \mathrm{mg} / \mathrm{kg} /$ day $(\mathrm{N}=5)$ & $\begin{array}{l}389 \pm 26.9 \\
(325-480)\end{array}$ & $\begin{array}{l}180.3 \pm 4.8 \\
(168.5-194.0)\end{array}$ & $\begin{array}{l}184.2 \pm 2.1 \\
(178.0-189.5)\end{array}$ & $\begin{array}{l}50.0 \pm 0.5 \\
(48.0-51.0)\end{array}$ & $\begin{array}{l}62.0 \pm 0.7 \\
(60.0-63.5)\end{array}$ \\
\hline $0.15 \mathrm{mg} / \mathrm{kg} /$ day $(\mathrm{N}=3)$ & $\begin{array}{l}332 \pm 38.8 \\
(255-380)\end{array}$ & $\begin{array}{l}177.0 \pm 8.5 \\
(160.0-186.5)\end{array}$ & $\begin{array}{l}183.3 \pm 2.4 \\
(180.0-188.0)\end{array}$ & $\begin{array}{l}48.7 \pm 0.3 \\
(48.0-49.0)\end{array}$ & $\begin{array}{l}60.5 \pm 1.0 \\
(58.5-61.5)\end{array}$ \\
\hline \multicolumn{6}{|l|}{ Females } \\
\hline DA Exposure Group & Birthweight & $\begin{array}{l}\text { Crown-Rump } \\
\text { Length }\end{array}$ & $\begin{array}{l}\text { Head } \\
\text { Circumference }\end{array}$ & $\begin{array}{l}\text { Head } \\
\text { Width }\end{array}$ & $\begin{array}{l}\text { Head } \\
\text { Length }\end{array}$ \\
\hline Controls $(\mathrm{N}=4)$ & $\begin{array}{l}309 \pm 19.0 \\
(255-340)\end{array}$ & $\begin{array}{l}169.1 \pm 4.4 \\
(161.5-181.5)\end{array}$ & $\begin{array}{l}179.5 \pm 3.4 \\
(171.5-187.0)\end{array}$ & $\begin{array}{l}48.3 \pm 1.3 \\
(46-0-51.0)\end{array}$ & $\begin{array}{l}59.8 \pm 1.2 \\
(57.0-62.5)\end{array}$ \\
\hline $0.075 \mathrm{mg} / \mathrm{kg} /$ day $(\mathrm{N}=4)$ & $\begin{array}{l}318 \pm 20.9 \\
(280-365)\end{array}$ & $\begin{array}{l}172.8 \pm 3.9 \\
(164.5-180.5)\end{array}$ & $\begin{array}{l}178.4 \pm 2.1 \\
(172.0-181.0)\end{array}$ & $\begin{array}{l}49.1 \pm 1.6 \\
(47.0-54.0)\end{array}$ & $\begin{array}{l}60.3 \pm 0.3 \\
(59.5-61.0)\end{array}$ \\
\hline $0.15 \mathrm{mg} / \mathrm{kg} /$ day $(\mathrm{N}=7)$ & $\begin{array}{l}304 \pm 19.6 \\
(240-365)\end{array}$ & $\begin{array}{l}173.4 \pm 2.8 \\
(164.0-183.0)\end{array}$ & $\begin{array}{l}177.9 \pm 2.0 \\
(170.0-182.5)\end{array}$ & $\begin{array}{l}47.3 \pm 0.6 \\
(45.0-49.0)\end{array}$ & $\begin{array}{l}58.9 \pm 0.7 \\
(56.0-60.5)\end{array}$ \\
\hline
\end{tabular}

Note: Significant differences between males and females for Birthweight $(\mathrm{p}=0.04)$, Head Circumference $(\mathrm{p}=0.02)$ and Head Length ( $\mathrm{p}=0.05)$. No significant DA exposure group differences or interaction of DA exposure and sex of the newborn for Infant Birth Characteristics. 


\section{Table 9:}

Mean \pm SE (Range) Apgar Scores ${ }^{1}$

\section{C-Section Delivery}

DA Exposure Group

Controls ( $\mathrm{N}=4$ )

Apgar 1

Apgar 2

$0.075 \mathrm{mg} / \mathrm{kg} /$ day $(\mathrm{N}=3)$

$7 \pm 0.8(6-12)$

$10 \pm 0.4(9-11)$

$0.15 \mathrm{mg} / \mathrm{kg} /$ day $(\mathrm{N}=3)$

$8 \pm 0.5$ (6-9)

$10 \pm 0.4(9-12)$

Vaginal Delivery

DA Exposure Group

$8 \pm 0.6(6-11)$

$10.0 \pm 0.6(7-12)$

Controls ( $\mathrm{N}=5$ )

Apgar 1

Apgar 2

$0.075 \mathrm{mg} / \mathrm{kg} / \mathrm{day}(\mathrm{N}=6)$

$12 \pm 0.3(11-12) \quad 11 \pm 0.4(10-12)$

$0.15 \mathrm{mg} / \mathrm{kg} / \mathrm{day}(\mathrm{N}=7)$

$11 \pm 0.3(11-12)$

$11 \pm 0.3(11-12)$

${ }^{1}$ Apgar 1 tested $\sim 5$ to 30 mins after delivery, Apgar 2 tested $\sim 1$ hour after delivery

${ }^{2} \mathrm{~N}=6$

Note: Significant differences between C-Section and Vaginal delivery for Apgar $1(\mathrm{p}=0.01)$. No significant DA exposure group differences or interaction of DA exposure and delivery type for Apgar scores 
Table 10:

Mean \pm SE (Range) Maternal and Newborn Plasma DA Concentrations ( $\mathrm{ng} / \mathrm{ml})$ at Delivery and Timing of Plasma Draw (Hours since Last Maternal Dose)

\begin{tabular}{lllll} 
DA Exposure Group & $\begin{array}{l}\text { Maternal DA } \\
\text { Concentration }\end{array}$ & $\begin{array}{l}\text { Timing of } \\
\text { Plasma Draw }\end{array}$ & $\begin{array}{l}\text { Newborn DA } \\
\text { Concentration }\end{array}$ & $\begin{array}{l}\text { Timing of } \\
\text { Plasma Draw }\end{array}$ \\
\hline $0.075 \mathrm{mg} / \mathrm{kg} /$ day $(\mathrm{N}=9)$ & $1.64 \pm 0.39^{1}$ & $\begin{array}{l}10.08 \pm 2.39 \\
(3.38-26.37)\end{array}$ & $\begin{array}{l}0.44 \pm 0.09 \\
(0.24-0.99)\end{array}$ & $\begin{array}{l}10.32 \pm 2.68^{2} \\
(3.75-26.57)\end{array}$ \\
& $(0.24-4.50)$ & & $1.26 \pm 0.32$ & $20.25 \pm 2.21$ \\
$0.15 \mathrm{mg} / \mathrm{kg} /$ day $(\mathrm{N}=10)$ & $\begin{array}{l}2.23 \pm 0.55 \\
(0.74-5.77)\end{array}$ & $\begin{array}{l}19.12 \pm 2.04 \\
(5.50-26.63)\end{array}$ & $(0.31-3.19)$ & $(5.73-27.38)$ \\
\hline
\end{tabular}

${ }^{1}$ For $0.075 \mathrm{mg} / \mathrm{kg} /$ day DA exposure group, mean calculations include 1 BLQ sample for maternal DA concentrations and 2 BLQ samples for newborn DA concentrations

${ }^{2} \mathrm{~N}=8$

Note: Significant effect of timing of plasma draw on maternal and newborn DA plasma concentrations ( $\mathrm{p}=0.01$ ). No significant DA exposure group differences in maternal DA plasma concentrations. Newborn DA plasma concentrations significantly higher in $0.15 \mathrm{mg} / \mathrm{kg} / \mathrm{day}$ DA exposure group $(\mathrm{p}=0.01)$. Maternal DA plasma concentrations significantly higher than newborn DA plasma concentrations $(\mathrm{p}<0.01)$. 